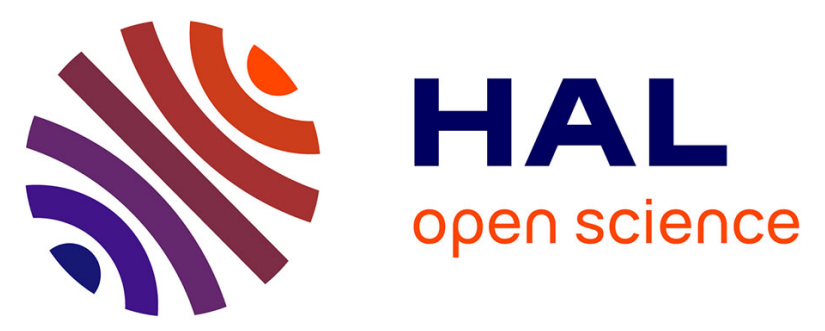

\title{
Leucettine L41, a DYRK1A-preferential DYRKs/CLKs inhibitor, prevents memory impairments and neurotoxicity induced by oligomeric A $\beta 25-35$ peptide administration in mice.
}

Gaëlle Naert, Valentine Ferré, Johann Meunier, Emeline Keller, Susanna

Malmstrom, Laurent Givalois, François Carreaux, Jean-Pierre Bazureau, Tangui Maurice

\section{- To cite this version:}

Gaëlle Naert, Valentine Ferré, Johann Meunier, Emeline Keller, Susanna Malmstrom, et al.. Leucettine L41, a DYRK1A-preferential DYRKs/CLKs inhibitor, prevents memory impairments and neurotoxicity induced by oligomeric $\mathrm{A} \beta 25-35$ peptide administration in mice.. European Neuropsychopharmacology, 2015, 25 (11), pp.2170-2182. 10.1016/j.euroneuro.2015.03.018 . hal-01146496

\section{HAL Id: hal-01146496}

\section{https://hal-univ-rennes1.archives-ouvertes.fr/hal-01146496}

Submitted on 16 Jun 2015

HAL is a multi-disciplinary open access archive for the deposit and dissemination of scientific research documents, whether they are published or not. The documents may come from teaching and research institutions in France or abroad, or from public or private research centers.
L'archive ouverte pluridisciplinaire HAL, est destinée au dépôt et à la diffusion de documents scientifiques de niveau recherche, publiés ou non, émanant des établissements d'enseignement et de recherche français ou étrangers, des laboratoires publics ou privés. 
Leucettine L41, a DYRK1A-preferential DYRKs/CLKs inhibitor, prevents memory impairments and neurotoxicity induced by oligomeric $A \beta_{25-35}$ peptide administration in mice

Gaëlle Naert, ${ }^{a, b}$ Valentine Ferré, $^{a}$ Johann Meunier, ${ }^{a, b}$ Emeline Keller, ${ }^{a, b}$ Susanna Malmström, ${ }^{\mathrm{a}, \mathrm{b}}$ Laurent Givalois, ${ }^{\mathrm{a}}$ François Carreaux, ${ }^{\mathrm{c}}$ Jean-Pierre Bazureau ${ }^{\mathrm{c}}$ and Tangui Maurice ${ }^{\mathrm{a}, \mathrm{b}, *}$

${ }^{a}$ Université Montpellier, INSERM U. 1198, place Eugène Bataillon, 34095 Montpellier cedex 5, France

${ }^{b}$ Amylgen, 2196, boulevard de la Lironde, 34980 Montferrier-sur-Lez, France

${ }^{c}$ Université Rennes, CNRS UMR 6226, Campus de Beaulieu, Bat. 10A, 10C, Avenue du Général Leclerc, 35042 Rennes cedex, France

* Corresponding author at: Inserm U1198, Université de Montpellier, cc 105, place Eugène Bataillon, 34095 Montpellier cedex 5, France. Tel: +33/0 467143623.

Email address: maurice@univ-montp2.fr 


\section{Abstract}

Dual-specificity tyrosine phosphorylation-regulated kinases (DYRKs) and cdc2-like kinases (CLKs) are implicated in the onset and progression of Down syndrome (DS) and Alzheimer's disease (AD). DYRK1A has emerged as a possible link between amyloid- $\beta(A \beta)$ and Tau, the major pathological proteins in AD. We here assessed the neuroprotective potential of a novel inhibitor of DYRKs/CLKs. The Leucettine L41, acting preferentially on DYRK1A, was tested in $A \beta_{25-35}$-treated mice, a nontransgenic model of $A D$-like toxicity. We co-injected intracerebroventricularly oligomeric $A \beta_{25-35}$ peptide and $L 41$ in Swiss male mice. After 7 days, they were submitted to behavioral tests addressing spatial and non-spatial, short- and longterm memories. The oxidative stress, apoptotic markers, kinases involved in Tau phosphorylation, and synaptic integrity were analyzed by western blot and ELISA in the hippocampus. $L 41$, tested at $0.4,1.2,4 \mu \mathrm{g}$, prevented the $A \beta_{25-35}$-induced memory deficits in the Y-maze, passive avoidance and water-maze tests, with the most active dose being $4 \mu \mathrm{g}$. The inhibitor prevented the $A \beta_{25-35}$-induced oxidative stress, as revealed by measures of lipid peroxidation levels and reactive oxygen species accumulation, and abolished $A \beta_{25-35}$-induced expression of pro-apoptotic markers. $L 41$ prevented the $A \beta_{25-35}$-induced decrease of $A K T$

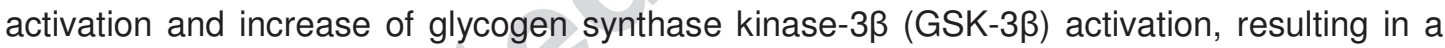
decrease of Tau phosphorylation. Finally, L41 restored $A \beta_{25-35}$-reduced levels of synaptic markers. The novel DYRK1A-preferential inhibitor L41 therefore prevented $A \beta_{25-35}$-induced memory impairments and neurotoxicity in the mouse hippocampus. These in vivo data highlighted particularly DYRK1A as a major kinase involved in $A \beta$ pathology and suggested therapeutic developments for DYRK1A inhibitors in AD.

\section{Key words:}

Kinase; DYRK1A; Leucettines; $A \beta_{25-35}$; amyloid toxicity; Tau phosphorylation. 


\section{Introduction}

Alzheimer's disease (AD), the most prevalent dementia in the elderly, is characterized by a progressive decline in executive and cognitive functions (Selkoe, 2002). The pathological diagnosis of this age-related disorder depends on the presence of both amyloid- $\beta(A \beta)$ plaques and intraneuronal tangles, consisting of hyper-phosphorylated Tau proteins (Selkoe, 2002). The $A \beta$ hypothesis of $A D$ pathophysiology posits that $A \beta$ induced the formation of Tau-containing neurofibrillary tangles and neuronal death, which contribute to progressively worsen cognitive abilities. Indeed, amyloid deposition is one of the processes that trigger the cascade of molecular events leading to neurofibrillary degeneration. Several kinases, mainly

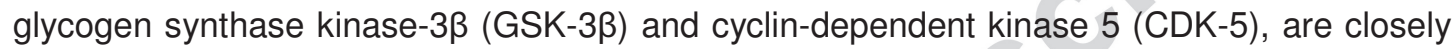
linked to $A D$ neuropathology and are a possible link between $A \beta$ and Tau (Flaherty et al., 2000; Iqbal et al., 2014).

Pre-phosphorylation of Tau by CDK-5 stimulates both the rate and extent of a subsequent phosphorylation catalyzed by GSK-3ß (Sengupta et al., 1997). In addition to Tau phosphorylation, GSK-3 $\beta$ and CDK-5 regulate $A \beta$ generation through phosphorylation of the cytoplasmic domain of APP (Aplin et al., 1996; lijima et al., 2000 and presenilin-1 (PS1) (Tesco and Tanzi, 2000; Lau et al., 2002). Despite these major roles in AD, inhibitors targeting these kinases have adverse effects in control group or depending on the $A D$ hallmarks studied (Ryder et al., 2003; Hu et al., 2009). Considering these adverse effects and their major constitutive functions, these kinases may not be appropriate therapeutic targets for AD. Targeting other kinase with greater central and lesser peripheral function should be a better alternative.

The dual-specificity tyrosine phosphorylation-regulated kinase 1A (DYRK1A) has emerged as a kinase potentially involved in $A D$ etiology. The first prima-facie evidence relates to the fact that DYRK1A gene is located on the chromosome 21, as the APP gene, a localization that supports DYRK1A implication in Down syndrome (DS) (Song et al., 1996; Kimura et al., 2007). Of great interest, DS subjects invariably develop AD at ages that are not usual in sporadic AD (de la Torre and Dierssen, 2012). In addition, DYRK1A mRNA 
expression was elevated in the hippocampus of AD patients (Kimura et al., 2007) and DYRK1A immunoreactivity was increased in the frontal and entorhinal cortex and in the hippocampus of AD patients (Ferrer et al., 2005). Moreover, DYRK1A phosphorylated Tau on 11 phosphorylation sites, which are phosphorylated in $\mathrm{AD}$, notably at $\mathrm{Thr}^{212}, \mathrm{Ser}^{202}, \mathrm{Thr}^{205}$ and $\mathrm{Thr}^{231}$ (Woods et al., 2001; Liu et al., 2008). As observed for major kinases involved in AD, DYRK1A can also phosphorylate APP (Ryoo et al., 2008) and PS1 (Ryu et al., 2010). Therefore, DYRK1A acts as a major kinase linking $A \beta$ and Tau and contributing to apoptotic processes in AD. However, several studies also showed that DYRK1A can directly regulate cell death. For instance, Dyrk1A is coupled to JNK1 activation, and directly interacts with apoptosis signal-regulating kinase 1 (ASK1) (Choi and Chung, 2011). Additionally in the Ts65Dn mouse model of DS, triplication of DYRK1A provoked retinal structural and functional alterations resulting in apoptosis (Laguna et al., 2013). The role of DYRK1A in AD related apoptosis must therefore be addressed.

The aim of this study was to determine whether a Dyrk1A preferential kinase inhibitor could be neuroprotective in a mouse model of amyloid toxicity. L41, a member of the Leucettine family of low molecular weight inhibitors, is derived from the marine sponge alkaloid Leucettamine B (Debdab et al., 2011; Tahtouh et al., 2012). L41 is a potent inhibitor of DYRK and CLK kinases, which acts preferentially on DYRK1A. The two major DYRK1A preferential inhibitors are epigallocatechin-3-gallate (EGCG; IC $\left.5_{50}=0.33 \mu \mathrm{M}\right)$ and harmine, which act also on other kinases (Adayev et al., 2011; Tahtouh et al., 2012). Comparatively to EGCG, harmine $\left(\mathrm{IC}_{50}=34-85 \mathrm{nM}\right)$ and $\mathrm{L} 41\left(\mathrm{IC}_{50}=10-60 \mathrm{nM}\right)$ induce enhanced inhibition rates for all isoforms of DYRK1A. L41 also inhibits DYRK1B $\left(\mathrm{IC}_{50}=44 \mathrm{nM}\right)$, DYRK2 $\left(\mathrm{IC}_{50}=\right.$ $73 \mathrm{nM}), \operatorname{CLK} 1\left(\mathrm{IC}_{50}=71 \mathrm{nM}\right), \mathrm{CLK} 4\left(\mathrm{IC}_{50}=64 \mathrm{nM}\right)$ and $\mathrm{GSK}-3 \alpha / \beta\left(\mathrm{IC}_{50}=210-410 \mathrm{nM}\right)$ (Tahtouh et al., 2012). However, among these L41 kinase targets, DYRK1A is the only one target of L41 identified in mouse brain by affinity chromatography approaches (Tahtouh et al., 2012; Burgy et al., 2013). In addition, identification of affinity chromatography purified L41 targets from various mouse tissues has revealed that expression pattern of it targets varies considerably from one organ to another, with the highest DYRK1A expression observed in brain (Tahtouh et al., 2012; Burgy et al., 2013). 
In the present study, we used a rapid model of $A \beta$ toxicity, consisting in intracerebroventricular (i.c.v.) injection of the $A \beta_{25-35}$ peptide (Maurice et al., 1996; Kaminsky et al., 2010) in oligomeric species (Zussy et al., 2013). $A \beta_{25-35}$ injection in mice and rats allows to assess the therapeutic potential of new compounds. It mimics the major hallmarks observed in $A D$, including memory deficits, oxidative stress, astrogliosis and microgliosis, neuroinflammation, pro-apoptotic caspases activity and loss of hippocampal and cholinergic neurons (Maurice et al., 1996; Kaminsky et al., 2010; Zussy et al., 2011). More particularly $A \beta_{25-35}$ enhanced Tau phosphorylation (Lahmy et al., 2013; Zussy et al., 2013) by activating involved kinases such as GSK-3ß (Lahmy et al., 2013). After determining the effective dose of $L 41$, we observed that $L 41$ prevented $A \beta_{25-35}$-induced cognitive impairments, spatial and non-spatial, short- and long-term memories in different behavioral tests. The neuroprotective effect of L41 was established for the dose of $4 \mu \mathrm{g}$ by analyzing the oxidative stress (lipid peroxidation, reactive oxygen species), Tau phosphorylation and activation of kinases (AKT, GSK-3 3 ) involved in this process, expression of apoptosis markers (Bax, Bcl2), and synaptic markers (PSD95, Synaptophysin, Arc and Egr1). 


\section{Experimental procedures}

\subsection{Animals}

Male Swiss mice (Depré, St-Doulchard, France), aged 7 weeks and weighing $32 \pm 2$ g, were used in this study. Animals, housed in groups had free access to food and water and were kept in a regulated environment $\left(22 \pm 1{ }^{\circ} \mathrm{C}, 40-60 \%\right.$ humidity, $12 \mathrm{~h}$ light/dark cycle with light on at 07:00 h). Experiments were carried out between 09:00 and 17:00. All animal procedures were conducted in adherence to the European Union Directive of September 22, 2010 (2010/63/UE).

\subsection{Drugs and administration procedures}

The amyloid- $\beta[25-35]\left(A \beta_{25-35}\right)$ and scrambled $A \beta_{25-35}$ (Sc. $\left.A \beta\right)$ peptides were purchased from Genepep (Saint-Jean-de-Védas, France). They were solubilized in distilled water at $3 \mathrm{mg} / \mathrm{ml}$ and stored at $-20^{\circ} \mathrm{C}$. Peptides were incubated at $37^{\circ} \mathrm{C}$ for 4 days, allowing $A \beta_{25-35}$, but not Sc.A $\beta$, to form oligomers (Zussy et al., 2013). They were administered i.c.v. as previously described in a final volume of $3 \mu \mathrm{l}$ per mouse (Maurice et al., 1996; Haley and McCormick (1957). Injection coordinates from Bregma were: AP $-0.4 \mathrm{~mm}, \mathrm{~L} 1.00 \mathrm{~mm}, \mathrm{~V}-2.50 \mathrm{~mm}$ (Paxinos and Franklin, 2012). The site of injection was confirmed a priori by indian ink in control animals. Leucettine L41, a potent inhibitor of DYRK and CLK kinases acting preferentially on DYRK1A, was produced as previously described (Debdab et al., 2011; Tahtouh et al., 2012; Burgy et al., 2013) and solubilized in dimethylsulfoxide (DMSO), 10\% in final dilution (Sigma-Aldrich, St Quentin-Fallavier, France). L41 or vehicle was coadministered i.c.v. $(1 \mu \mathrm{l}$ per mouse) at different doses: $0.4,1.2$ and $4 \mu \mathrm{g}$, corresponding respectively to $1.3,3.9$ and $13 \mathrm{nmol}$. These doses have been chosen to favor a specific action of $L 41$ on DYRK1A, considering the protein kinase selectivity of $L 41$ : DYRK1A $\left(I_{50}=\right.$ 10-60 nM), DYRK1B $\left(I_{50}=44 \mathrm{nM}\right)$, DYRK2 $\left(\mathrm{IC}_{50}=73 \mathrm{nM}\right)$, DYRK3 $\left(\mathrm{IC}_{50}=320 \mathrm{nM}\right)$, DYRK4 $\left(I_{50}=520 \mathrm{nM}\right), \operatorname{CLK} 1\left(\mathrm{IC}_{50}=71 \mathrm{nM}\right), \mathrm{CLK} 4\left(\mathrm{IC}_{50}=64 \mathrm{nM}\right)$ and $\mathrm{GSK}-3 \alpha / \beta\left(\mathrm{IC}_{50}=210-410\right.$ $\mathrm{nM})$. At the dose we used $(4 \mu \mathrm{g}, 13 \mathrm{nmol})$, the L41 would be active preferentially on the DYRK1A kinase. 


\subsection{Spontaneous alternation performances}

Each mouse was allowed to freely explore a Y-maze (three arms, $50 \mathrm{~cm}$ long, $60^{\circ}$ separate) during a single 8-min session (Maurice et al., 1996). An alternation was defined as entries into all three arms on consecutive trials. The percentage of alternation was calculated as: actual alternations / total possible alternations $\times 100$.

\subsection{Step-through passive avoidance test}

Each mouse was placed into the white compartment of a two-compartment apparatus. After $5 \mathrm{~s}$, the guillotine door was raised. When the mouse entered the darkened compartment, a scrambled footshock was delivered through the gridfloor (s (0.3 mA for $3 \mathrm{~s}$; Lafayette Instruments, Lafayette, MA, USA). The step-through latency and sensitivity to the shock were recorded. The latter was evaluated as: $0=$ no sign; $1=$ flinching reactions; $2=$ flinching and vocalization reactions. None of the treatments used in the present study affected latency or shock sensitivity during training (not shown). $24 \mathrm{~h}$ after training, each mouse was placed again into the white compartment. The step-through and escape latencies, i.e., the latency to re-exit from the dark compartment, were recorded up to $300 \mathrm{~s}$.

\subsection{Place learning in the water maze}

The water-maze was a circular pool (diameter $140 \mathrm{~cm}$, height $40 \mathrm{~cm}$ ). Water temperature, 23 $\pm 1{ }^{\circ} \mathrm{C}$, light intensity, external cues in the room, and water opacity were unchanged. $\mathrm{A}$ transparent Plexiglas platform (diameter $10 \mathrm{~cm}$ ) was immersed under the water surface. Swimming was recorded using the Videotrack ${ }^{\circledR}$ software (Viewpoint, Champagne-au-Montd'Or, France), with trajectories being analyzed as latencies and distances. The software divides the pool into four quadrants.

Acquisition: between days 7 to 11 after peptide injection, training consisted in 3 swims per day, with 20 min intertrial time interval. Start positions, at limits between quadrants, were randomly selected and mice were allowed up to $90 \mathrm{~s}$ swim to find the platform. Animals were left on the platform during $20 \mathrm{~s}$. The median latency was calculated for each training day. 
Retention: a probe test was performed after $24 \mathrm{~h}$. The platform was removed and each animal was allowed a free $60 \mathrm{~s}$ swim. The time spent in the training $(\mathrm{T})$ quadrant was analyzed.

\subsection{Lipid peroxidation measures}

Mice were killed by decapitation and brains rapidly dissected out, weighed and stored in liquid nitrogen. Hippocampi were homogenized in cold methanol (1/10, w/v), centrifuged at $1,000 \mathrm{~g}$ during $5 \mathrm{~min}$ and supernatant collected. Homogenate was added to a solution containing $\mathrm{FeSO}_{4} 1 \mathrm{mM}, \mathrm{H}_{2} \mathrm{SO}_{4} 0.25 \mathrm{M}$, xylenol orange $1 \mathrm{mM}$, and incubated for $30 \mathrm{~min}$ at room temperature. Absorbance was measured at $580 \mathrm{~nm}\left(\mathrm{~A}_{580} 1\right)$, and $10 \mu \mathrm{l}$ of cumene hydroperoxide (CHP) $1 \mathrm{mM}$ was added and the sample incubated for $30 \mathrm{~min}$ at room temperature, to determine the maximal oxidation level. Absorbance was measured at $580 \mathrm{~nm}$ $\left(A_{580} 2\right)$. The lipid peroxidation level was determined as CHP equivalents according to: CHP equiv. $=A_{580} 1 / A_{580} 2 \times(C H P(n m o l)) \times$ dilution.

\subsection{Measurement of reactive oxygen species (ROS)}

ROS accumulation was determined by analyzing 2',7'-dichlorofluorescein (DCF) fluorescence. DCF diacetate $(0.5 \mu \mathrm{M})$ (Sigma-Aldrich) was applied to the hippocampus extract. DCF diacetate was readily converted into DCF, able to interact with peroxides (primarily $\mathrm{H}_{2} \mathrm{O}_{2}$ ) to form fluorescent DCF. DCF fluorescence was quantified (excitation 485 $\mathrm{nm}$, emission $530 \mathrm{~nm}$ ) using a Fluoroskan Ascent spectrofluorimeter (Thermo Scientific, Waltham, USA), normalized for protein concentration.

\subsection{Western blotting}

Mice were decapitated 1, 3, 5 and 7 days after $A \beta_{25-35}$ peptide injection. Hippocampi were removed on ice-cold glass plate and stored at $-80^{\circ} \mathrm{C}$. Hippocampal tissues were homogenized by sonication in a lysis buffer (125 mM Tris-HCl pH 6.8, 4\% SDS, $20 \%$ glycerol) including a protease and phosphatase inhibitors cocktail (Roche Diagnostics, Germany). Homogenates were heated at $70^{\circ} \mathrm{C}$ for 10 min and centrifuged at $16,000 \mathrm{~g}$ for 30 
min at $4^{\circ} \mathrm{C}$. Protein concentration was determined using a BCA assay (Pierce Biotechnology, Rockford, USA). Proteins, 20-40 $\mathrm{\mu g}$ per lane, were resolved on a $12 \%$ sodium dodecylsulfate-polyacrylamide gel and then transferred electrophoretically to a polyvinylidene difluoride membrane (GE Healthcare, France). After $1 \mathrm{~h}$ blocking in $5 \%$ non-fat dry milk in a $20 \mathrm{mM}$ Tris-buffered saline, $\mathrm{pH} 7.5$, buffer containing $0.1 \%$ Tween-20, membranes were incubated overnight at $4^{\circ} \mathrm{C}$ with the primary antibodies (Table 1). After brief washes, membranes were incubated for $1 \mathrm{~h}$ at room temperature with corresponding secondary antibody (Table 1). The immunoreactive bands, visualized using enhanced chemiluminescence reagent (Pierce Biotechnology) were quantified using a quantitative fluorescence imaging system (Odyssey Fc, Li-Cor ScienceTec, France). Results were corrected with the corresponding $\beta$-tubulin ( $\beta$-tub) level.

\subsection{Synaptic marker measures}

Hippocampi were homogenized in cold PBS. The content in synaptic markers -Arc, Egr1, PSD-95 and synaptophysin - were analyzed using ELISA kits (USCN Life Science, Euromedex, Souffelweyersheim, France). Levels in synaptic markers were expressed as $\mathrm{ng} / \mathrm{mg}$ hippocampus wet weight.

\subsection{Experimental series}

As schematized in Figure 1, the first experimental series address the dose-response effect of $\mathrm{L} 41$ in $\mathrm{A} \beta_{25-35}$-treated mice. L41 was injected at the doses of $0.4,1.2,4 \mu \mathrm{g} / \mathrm{mouse}$ i.c.v. and animals were tested in the spontaneous alternation and passive avoidance tests. After retention, animals were sacrificed, their brain dissected out and their hippocampus used for lipid peroxidation measures. In the second experimental series, animals were treated with L41 at the most active dose, i.e., $4 \mu \mathrm{g} / \mathrm{mouse}$, and used for place learning in the water-maze, and biochemical analyses (DCF, kinase activity, Tau phosphorylation and synaptic markers). For the latter, the Sc.Aß/L41-treated group was added as a drug-alone control group. 


\subsection{Statistical analyses}

Biochemical and behavioral data were expressed as mean \pm SEM, except step-down latencies expressed as median and interquartile range. They were analyzed using one-way ANOVA ( $F$ values), followed by the Dunnett's post hoc multiple comparison test. Passive avoidance latencies, expressed as median and interquartile (25\%-75\%) range, were analyzed a Kruskal-Wallis nonparametric ANOVA ( $H$ values), as upper cut-off times were set, followed by the Dunn's multiple comparison test. Acquisition profiles in the water-maze were analyzed using the non-parametric repeated-measure Friedman's ANOVA (Fr value), followed by a Mann-Whitney's test for post-hoc comparisons. Probe test data were presented as time spent in the quadrants. Presence in the T quadrant was analyzed using a onesample $t$-test $v s$. the chance level (15 s). The level of statistical significance was $p<0.05$.

\section{Results}

3.1. The Leucettine $L 41$ prevented $A \beta_{25-35}$-induced spatial and non-spatial, short- and long-term memory impairments

To determine whether $L 41$ possessed neuroprotective properties, we co-administered L41 with $A \beta_{25-35}$, in the 0.4-4 $\mu \mathrm{g}$ dose-range. The spatial working memory was assessed using spontaneous alternation in the Y-maze (Fig. 2a,b). The deficits observed in mice treated with $A \beta_{25-35}$ were dose-dependently and significantly prevented in mice co-administered with $L 41$, particularly at the doses of 1.2 and $4 \mu \mathrm{g}$ (Fig. 2a). In parallel, none of the treatments affected the locomotor and exploratory responses, measured in terms of number of arms entries (Fig. $2 b)$. Non-spatial long-term memory was assessed using the passive avoidance procedure (Fig. 2c,d). None of the treatments affected the step-through latency and sensitivity to the shocks, during the training session (data not shown). During the retention session, the $A \beta_{25-35}$ treatment provoked a significant decrease in step-through latency (Fig. 2c) and an increase in escape latency (Fig. $2 d$ ) (t test $p=0.065$ vs. Sc.A $\beta$ V). L41 co-administration prevented the $A \beta_{25-35}$-induced deficits, a significant effect being measured at the dose of $4 \mu \mathrm{g}$ for the 
step-through latency (Fig. 2c).

The efficacy of L41 $(4 \mu \mathrm{g})$ was analyzed on long-term spatial memory using place learning in the water-maze (Fig. 3). Analyses of acquisition profiles showed that the latencies measured for the Sc.A $\beta / V$-treated group significantly decreased over training trials (Fig. 3a). By contrast, $A \beta_{25-35}$ failed to show any significant decrease in latency indicating an impairment of memory acquisition (Fig. 3a). Indeed, latencies measured during trials 4 and 6 were significantly higher than those measured for the Sc.A $/ V$ control group. The L41 coadministration restored learning capacity, as shown by the significant decrease in swimming duration, with significant differences measured from trial 3 to trial 6 as compared to $A \beta_{25-35} / \mathrm{V}$ treated animals (Fig. 3b). Analysis of the animal presence in the training (T) quadrant of the pool during the probe test showed that Sc.A $/ \mathrm{V}$-treated animals spent significantly more time in this quadrant than hazard level (15 s), confirming an effective learning of the platform location (Fig. 3c). The presence of the $A \beta_{25-35} / \mathrm{V}$-treated group remained non-significantly different from the hazard level, indicating a failure to acquire the platform location (Fig. 3c). L41 co-administration significantly prevented the deficit (Fig. 3c). To note, none of the treatment altered the swimming speed of the animals during the probe test session (Fig. 3d).

\section{2. $L 41$ decreased $A \beta_{25-35}$-induced oxidative stress in mice hippocampus}

To assess the effect of $A \beta_{25-35}$ on oxidative stress in the mouse hippocampus, we measured the level of lipid peroxidation $1,3,5$ and 7 days after the icv injection of the peptide. $A \beta_{25-35}$ significantly increased lipid peroxidation, 5 and 7 days after injection (Fig. 4a). L41, at $4 \mu \mathrm{g}$, prevented significantly the $A \beta_{25-35}$-induced increase in lipid peroxidation level (Fig. 4b). $A$ second assay of oxidative stress in mice hippocampus was performed by an indirect quantification of ROS accumulation using the measurement of DCF fluorescence. It was significantly increased 7 days after $A \beta_{25-35}$ injection (Fig. 4c). L41, at the dose of $4 \mu \mathrm{g}$, abolished the $A \beta_{25-35}$-induced increase in DCF fluorescence (Fig. $4 \mathrm{~d}$ ). To note L41 alone had no effect on DCF fluorescence (Fig. 4d). 


\subsection{L41 blocked $A \beta_{25-35}$-induced GSK-3 $\beta$ activation and Tau phosphorylation in mice} hippocampus

In order to analyze the effect of L41, injected at $4 \mu \mathrm{g} /$ mouse, on GSK-3 $\beta$ activation in hippocampus, we determined the level of phosphorylation on $\mathrm{Ser}^{473}$ for Akt, and $\mathrm{Tyr}^{216}$ and Ser $^{9}$ for GSK-3 $\beta$ (Fig. 5). Indeed, $\mathrm{P}\left(\mathrm{Ser}^{473}\right)$ Akt is an indirect measure of Akt activity, which is responsible notably for $\mathrm{Ser}^{9}$ phosphorylation on GSK-3ß, which inactivates the kinase. Phosphorylation on $\mathrm{Tyr}^{216}$ is on the contrary linked to GSK-3 $\beta$ activation. $A \beta_{25-35}$ injection rapidly and transiently decreased $\mathrm{P}\left(\mathrm{Ser}^{473}\right)$ Akt/Akt ratio (Fig. 5a). Co-administration of L41 partially but significantly prevented the decrease in $\mathrm{P}\left(\mathrm{Ser}^{473}\right)$ Akt/Akt ratio, 1 day after i.c.v. injections (Fig. 5b). Rapidly and long-lastingly until 7 days after $A \beta_{25-35}$ injection, the

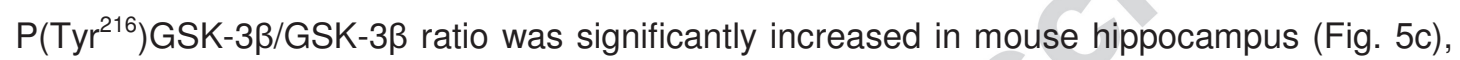

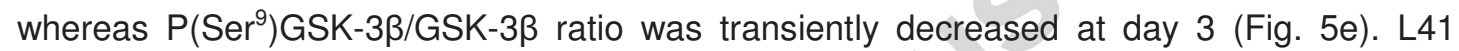
prevented the $A \beta_{25-35}$-induced increase in $P\left(\mathrm{Tyr}^{216}\right)$ GSK-3 $\beta / G S K-3 \beta$ ratio, 7 days after i.c.v. injections (Fig. 5d). The DYRK1A preferential inhibitor also significantly decreased the basal level of $\mathrm{P}\left(\mathrm{Tyr}^{216}\right)$ GSK-3 $\beta$ (Fig. $5 \mathrm{~d}$ ). In addition, L41 also prevented the decrease in $P\left(\right.$ Ser $\left.^{9}\right)$ GSK-3 $\beta /$ GSK-3 $\beta$ ratio, on day 3 (Fig. $\left.5 f\right)$. Here again, the basal level of $P\left(\right.$ Ser $\left.^{9}\right)$ GSK$3 \beta$ was decreased by L41 (Fig. 5f).

In summary, $A \beta_{25-35}$ induced a global increase of GSK-3 $\beta$ activity, as revealed by decreased $\mathrm{P}\left(\mathrm{Ser}^{473}\right)$ Akt/Akt ratio (decreased Akt activity) and both decreased $\mathrm{P}\left(\mathrm{Ser}^{9}\right)$ GSK$3 \beta / G S K-3 \beta$ ratio and increased $P\left(\operatorname{Tyr}^{216}\right)$ GSK-3 $\beta /$ GSK- $3 \beta$ ratio. This $A \beta_{25-35}$-induced increase of GSK-3 $\beta$ activity was prevented by $L 41$.

In addition, $A \beta_{25-35}$ provoked a robust increase of Tau phosphorylation on $\mathrm{Ser}^{202} / \mathrm{Thr}^{205}$, a physiological epitope recognized by the AT8 antibody (Fig. 6a, c). A $\beta_{25-35}$ showed only a tendency to increase Tau phosphorylation on $\operatorname{Thr}^{212} / \operatorname{Ser}^{214}(+41 \%$, ns), a pathological epitope recognized by the AT100 antibody (Fig. 6b, c). L41 partially, but significantly, prevented the $A \beta_{25-35}$-induced Tau phosphorylation on $\mathrm{Ser}^{202} / \mathrm{Thr}^{205}$ (Fig. 6a, c). The DYRK1A inhibitor had only a marginal effect on Tau phosphorylation on $\mathrm{Thr}^{212} / \mathrm{Ser}^{214}$ (Fig. 6b, c). 
3.4. L41 prevented $A \beta_{25-35}$-induced pro-apoptotic pathways and disrupted synaptic integrity

The protective properties of $L 41$, injected at $4 \mu \mathrm{g} / \mathrm{mouse}$, on neuronal integrity were also analyzed. $A \beta_{25-35}$ triggered activation of the apoptotic pathway (Fig. 7). Indeed, time-course analysis of the expression of the pro-apoptotic protein Bax revealed a sustained increase in the hippocampus after $A \beta_{25-35}$ injection (Fig. 7a). The highest level was observed 7 days after $A \beta_{25-35}$ injection. The co-administration of $L 41$ prevented this increase of Bax expression (Fig. $7 b)$. In addition, 7 days after injection, $A \beta_{25-35}$ induced a significant decrease in the expression of the anti-apoptotic protein Bcl-2 (Fig. 7C). $L 41$ is prevented the $A \beta_{25-35}$-induced decrease in $\mathrm{Bcl}-2$ (Fig. 7c). As Bax and Bcl-2 can form heterodimers, determination of the Bax/Bcl-2 ratio is highly relevant. The Bax/Bcl-2 ratio was calculated for each animal of the different groups. It appeared robustly increased after $A \beta_{25-35}$ injection (Fig. $7 d$ ), while $L 41$ fully prevented this increase (Fig. 7d).

In addition, the level of pro-caspase 9 was also determined in the hippocampus. $A \beta_{25-}$ ${ }_{35}$ induced, 7 days after injection, a significant increase in pro-caspase 9 expression (Fig. 7e). L41 prevented the increase in pro-caspase 9 expression triggered by $A \beta_{25-35}$ (Fig. 7e).

The synaptic integrity was assessed in the mouse hippocampus by determining the level of several synaptic markers, 7 days after injection. The levels of Arc, Egr1, PSD95 and synaptophysin were significantly lowered in $A \beta_{25-35}$ treated mice by $-25 \%,-18 \%,-54 \%$ and $19 \%$, respectively (Fig. $8 \mathrm{a}-\mathrm{d}$ ). The co-administration of $\mathrm{L} 41$ prevented the $A \beta_{25-35}$-induced decrease of Arc, PSD95 and synaptophysin levels (Fig. 8a,c,d). A marginal effect was measured on Egr1 expression. To note, L41 had no effect on these parameters in Sc.Aßtreated animals. 


\section{Discussion}

Kinases are major players in the etiology and progression of AD. However, to date, the most studied kinases, GSK-3 $\beta$ and CDK5, revealed poor therapeutic potentials. We here analyzed the implication of a less investigated kinase, DYRK1A, in an animal model of $A \beta$ toxicity. Our results highlighted for the first time a role of DYRK1A in amyloid toxicity and suggested that DYRK1A inhibitors could be promising new therapeutic compounds for AD.

We used the acute model of $A \beta$ toxicity where $A \beta_{25-35}$ i.c.v. injection provoked rapidly and sustainably an AD-like toxicity and learning and memory impairments (Maurice et al., 1996; Kaminsky et al., 2010; Zussy et al., 2011). Seven days after injection, $A \beta_{25-35}$-treated mice exhibited deficits in spontaneous alternation, passive avoidance response and spatial learning in the water-maze. We demonstrated that L41 was able to prevent the onset of these cognitive impairments when the drug was co-administered with $A \beta_{25-35}$. Similarly to harmine, L41 is an inhibitor of DYRKs and CLKs, two related families of kinases, some members of which are involved in the onset and development of AD and DS, and acting preferentially on DYRK1A. L41 and harmine showed consistently similar inhibition rates for DYRK1A and CLK1. L41 displays neuroprotective properties in vitro (Tahtouh et al., 2012). Indeed, it provoked a dose-dependent inhibition of the neurodegeneration induced by APP in cultured cells, with a more robust effect than harmine. In addition, a specific knockdown of DYRK1A expression by siRNA inhibited neurodegeneration induced by APP (Tahtouh et al., 2012), suggesting a major role of DYRK1A in APP-induced neurotoxicity. These in vitro studies revealed that the pharmacological or genetic inhibition of DYRK1A activity seems to be a promising approach to counteract $A \beta$-induced neurodegeneration. In addition, harmine, used as the same doses as L41, induced neuroprotective effects in mice brain when coadministered i.c.v. with $A \beta_{25-35}$, but to a lesser extend than L41 (unpublished data), suggesting that $L 41$ would be a better pharmacological tool.

As observed in $A D$, we have previously shown an increase of GSK-3ß activity in the $A \beta_{25-35}$ mouse model (Lahmy et al., 2013). This result confirms previous data demonstrating $A \beta_{25-35}$-induced GSK-3 $\beta$ activity in primary cultures of hippocampic neurons (Takashima et 
al., 1998). Here, we have clearly shown that $L 41$ inhibited the $A \beta_{25-35}$-induced GSK-3 $\beta$ activity in mice hippocampus. This L41 effect on GSK-3 $\beta$ could occur by both direct and indirect mechanisms. In vitro studies showed that L41 interacts both with DYRK1A and GSK$3 \beta$ and reduced their activity (Tahtouh et al., 2012; Burgy et al., 2013). Among all L41 kinase targets enriched from mouse brain, DYRK1A and GSK-3 are the two kinases interacting with L41 identified by affinity chromatography approaches (Tahtouh et al., 2012). However, L41 treatment $(0.01$ to $10 \mu \mathrm{M})$ of mouse hippocampal cell lines did not affect GSK-3 activity, but reduced robustly DYRK1A activity (Tahtouh et al., 2012). Although the dose used in this culture experiment is 1000 time higher than the one used in our study (13 nmol), L41 failed to affect GSK-3 activity. Therefore, the decreased activity of GSK-3 $\beta$ observed in our study

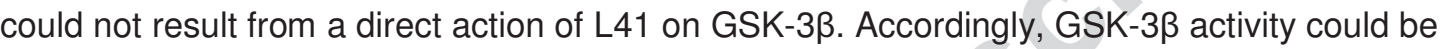
modulated by L41 effect on other kinases regulating GSK-3ß. Indeed, its activity depends on phosphorylation at specific sites. Ser ${ }^{9}$ phosphorylation is related to inhibition of GSK-3 $\beta$ activity, whereas phosphorylation on its $\mathrm{Tyr}^{216}$ results in activation (Medina et al., 2011). Many protein kinases, including Akt, are competent at phosphorylating GSK-3ß on Ser $^{9}$ (Fang et al., 2000; Medina et al., 2011). Once activated, as revealed by its phosphorylation on $\mathrm{Ser}^{473}$, Akt phosphorylates GSK-3 $\beta$ on its inhibitory residue, $\mathrm{Ser}^{9}$ (Fang et al., 2000). Although $A \beta_{25-35}$ inhibited Akt activity, L41 was able to prevent this Akt inhibition. This L41 effect on Akt would certainly contribute to the inhibition of GSK-3 $\beta$ activity. In addition, L41 interacts predominantly with DYRK1A, which acts as a priming kinase. Indeed, DYRK1A phosphorylates Tau on different residues enhancing then it phosphorylation by other kinases on distinct sites (Woods et al., 2001). Therefore, L41 could also affect GSK-3 $\beta$ activity by a reduction of these priming effects. In addition, L41 could also affect GSK-3 $\beta$ activity by an indirect effect, as previously described for other kinase inhibitors. Indeed, CDK5 inhibitor increased GSK-3 $\beta$ activity by a CDK5-mediated direct modulation of phosphatases inducing Ser ${ }^{9}$ dephosphorylation (Morfini et al., 2004). Although such effect has not yet been reported for DYRK1A, we cannot exclude that L41 can affect phosphatase activity. Therefore, the decrease of Tau phosphorylation induced by $L 41$ could be explained by a decreased activity of kinases involved in this process, such as GSK-3 $\beta$ and DYRK1A, but also by a reduction of 
the priming function of DYRK1A. More in details, $A \beta_{25-35}$ increased Tau phosphorylation at $\mathrm{Ser}^{202}$ and $\mathrm{Thr}^{205}$, but had no effect on it phosphorylation at $\mathrm{Thr}^{212}$ and $\mathrm{Ser}^{214}$. L41 had no effect on these different phosphorylations in basal conditions, i.e., in Sc.AB/L41-treated animals. By contrast, $L 41$ is able to prevent partially the $A \beta_{25-35}$ induced increase of Tau phosphorylation at $\mathrm{Ser}^{202}$ and $\mathrm{Th}^{205}$, suggesting that other kinases are involved. The lack of L41 effect on Tau phosphorylation at $\mathrm{Thr}^{212}$ and $\mathrm{Ser}^{214}$ could be explained by the absence of $A \beta_{25-35}$ effect. Despite the ability of DYRK1A to phosphorylate Tau at $\mathrm{Thr}^{212}$ (Woods et al., 2001; Liu et al., 2008), some discrepancy on the role of DYRK1A in $\mathrm{Thr}^{212}$ phosphorylation has been reported in the literature. Depending on the transgenic mice model overexpressing DYRK1A and the mouse age, $\mathrm{Thr}^{212}$ phosphorylation can involve DYRK1A activity (Ferrer et al., 2005; Liu et al., 2008; Sheppard et al., 2012). Furthermore, DYRK1A-mediated Tau phosphorylation primed further phosphorylation at $\mathrm{Ser}^{199}, \mathrm{Ser}^{202}, \mathrm{Thr}^{205}$ and $\mathrm{Ser}^{208}$ by GSK$3 \beta$ (Woods et al., 2001; Liu et al., 2008), suggesting a general role for DYRK1A in Tau phosphorylation. In our model, DYRK1A seems not to affect Tau phosphorylation at $\mathrm{Thr}^{212}$ and, thus would not prime Tau phosphorylation by GSK-3ß. Then, L41, having no effect on $\mathrm{Thr}^{212}$ phosphorylation, would not affect Tau phosphorylation by GSK-3 $\beta$ through the DYRK1A priming activity.

A well-characterized hallmark of $A \beta$ toxicity is oxidative stress. In the $A \beta_{25-35}$ model, lipid peroxidation and ROS accumulation were increased and the co-administration of L41 prevented this $A \beta_{25-35}$-induced oxidative stress. Therefore, L41 exhibited antioxidant properties, as observed for other DYRK1A preferential inhibitors the EGCG (Mandel et al., 2008) and harmine (Reus et al., 2010). Moreover $A \beta_{25-35}$ injection also induced pro-apoptotic pathways as revealed by the rapid and sustained increase of Bax protein expression. At the same time, the expression of an anti-apoptotic protein, Bcl-2, is greatly decreased. These results are consistent with altered expression levels of $\mathrm{Bcl}-2$ family proteins observed in $A D$ (Kitamura et al., 1998). Concomitantly, $A \beta_{25-35}$ enhanced the level of pro-caspase 9. L41 is able to prevent this $A \beta_{25-35}$-induced pro-apoptotic pathway and pro-caspase expression. This L41 effects are of great interest and suggest the involvement of DYRKs/CLKs and particularly DYRK1A in this $A \beta_{25-35}$-induced pro-apoptotic pathways. One explanation is that 
DYRK1A regulates pro-apoptotic pathways through regulation of GSK-3 $\beta$ activity. Indeed, a recent in vitro study highlighted that GSK-3 is able to directly enhance Bax activity in neuron cells (Ngok-Ngam et al., 2013). In addition, previous studies demonstrated that fibrillar and oligomeric $A \beta$ induced cell death through a Bax-dependent mechanism (Giovanni et al., 2000; Kudo et al., 2012). However, it remains unknown how oligomeric or fibrillar $A \beta$ activates Bax, one potential pathway being kinase activation. Indeed, $A \beta$ is known to activate c-Jun N-terminal kinase (JNK). CDK kinases, more particularly CDK4, seem also to be involved in this $A \beta$-induced apoptotic pathway (Giovanni et al., 2000). Here, we demonstrated that a DYRK1A-preferential inhibitor prevented the induction of pro-apoptotic pathways. This effect could be explained by a coupling of DYRK1A to JNK1 activation, directly interacting with apoptosis signal regulating kinase 1 (ASK1). Moreover, DYRK1A positively regulates ASK1-mediated JNK1-signaling, and appears to directly phosphorylate ASK1 (Choi and Chung, 2011). Therefore, DYRK1A is able to modulate apoptotic markers expression and activity and plays a key role in ASK1-mediated transmission of cell death signals.

The first signs of $A D$ occur with subtle alterations in the hippocampal synaptic activity prior to frank neuronal degeneration (Selkoe, 2002). Soluble $A \beta$ species may affect synaptic functions since it abrogates synaptic plasticity, induces memory impairments and interferes with normal activity and trafficking of several synaptic receptors (Ma and Klann, 2011). Moreover the expression of genes critical for memory or neuroprotection in hippocampus is affected by $A \beta$ (Dickey et al., 2004) and both intra- and extracellular $A \beta$ has the ability to affect their expression (Wegenast-Braun et al., 2009). This gene expression reduction have been previously described in $\mathrm{APP}_{\text {swe }} / \mathrm{PS} 1$ mice and occurred concomitantly with onset of the cognitive decline (Naert and Rivest, 2012). Here, $A \beta_{25-35}$ induced a decrease expression of Arc, Egr1, PSD95 and synaptophysin, concomitantly with learning and memory impairments, and both synaptic marker reduction and memory deficit can be prevented by the coadministration of L41. The immediate early genes Arc and Egr1 are clearly involved in learning and memory processes in hippocampus. The postsynaptic density protein-95 (PSD95) is a molecule critical for synaptic plasticity (Malinow and Malenka, 2002). This deficit in 
synaptic markers could explain, at least in part, the $A \beta_{25-35}$-induced memory and learning impairments. Indeed, the occurrence of cognitive impairment is correlated with a decline in Arc and Egr1 expression levels during aging (Blalock et al., 2003) and in AD transgenic mice model (Dickey et al., 2004; Naert and Rivest, 2012). PSD-95 is involved in recruiting and holding glutamate receptors at the surface (Xiao et al., 1998) and Arc expression is also closely related to N-methyl-D-aspartate (NMDA) receptor activity (Bloomer et al., 2008). Down-regulation of these genes clearly affects synaptic plasticity processes underlying longterm potentiation and memory in $A D$.

In conclusion, this in vivo study reveals for the first time the major role of DYRK1A in $A \beta$ toxicity. Although the pharmacological inhibitor Leucettine 41 targets DYRKs/CLKs, L41 effects on $A \beta$ toxicity seem to be attributed to inhibition of DYRK1A in particular, as DYRK1A is the main target of L41 in mouse brain. Due to DYRK1A involvement in Tau hyperphosphorylation, its role in $A \beta$ toxicity validates DYRK1A as key kinase of $A D$. Targeting DYRK1A in a therapeutic strategy would permit to act on the two major component of $A D$, Tau hyperphosphorylation and $A \beta$ pathology. Thus, the Leucettine $L 41$, and the other members of the Leucettine family, constitutes promising therapeutic compounds to counteract the development and the progression of $A D$. 


\section{Role of funding sources}

This work was supported by a "Fond Unique Interministériel" (FUI-OSEO, Paris, France) funding, project "Pharmasea", and a public funding from the Région Languedoc-Roussillon (ARPE, Montpellier, France).

\section{Contributors}

G.N. designed and performed experiments, analyzed the data and wrote the manuscript. V.F., J.M., S.M. and L.G. performed part of the experiments. L.G. corrected the manuscript. F.C. and J.P.B. synthetized the compound and implemented the study plan and manuscript. T.M. designed the experiments, analyzed the data and wrote the manuscript.

\section{Conflict of interest}

J.M., E.K. and S.M. are employees of Amylgen. T.M. is a member of the scientific advisory board of Anavex Life Sciences and scientific director of Amylgen. Other authors declare no conflict of interest. Amylgen had no funding nor scientific role in the present research.

\section{Acknowledgments}

We acknowledge Philippe Clair for his help to use LiCor Odyssey FC instrument at "qPHD UM2/Montpellier GenomiX" facility and Dr. Laurent Meijer (ManRos Therapeutics, Roscoff, France) for helpful discussions. 
Table 1 Antibodies used in Western blot experiments

\begin{tabular}{|c|c|c|c|c|c|}
\hline Protein & $M W$ & Primary antibody & dilution & Ref. & Supplier \\
\hline \multicolumn{6}{|c|}{ Primary antibodies } \\
\hline pAkt & $70 \mathrm{KDa}$ & rabbit anti-P(S $\left.\mathrm{S}^{473}\right)$-Akt & $1: 2000$ & 9271 & Cell Signaling Technol. \\
\hline Akt & $70 \mathrm{KDa}$ & rabbit anti-Akt & $1: 2000$ & 9272 & Cell Signaling Technol. \\
\hline pGSK-3 $\beta$ & $46 \mathrm{KDa}$ & mouse anti-P(Y216)-GSK-3 $\beta$ & $1: 2000$ & 612313 & BD Biosciences \\
\hline pGSK-3 $\beta$ & $46 \mathrm{KDa}$ & rabbit anti-P(S $\left.{ }^{9}\right)-G S K-3 \beta$ & $1: 2000$ & 9336 & Cell Signaling Technol. \\
\hline GSK-3 $\beta$ & $46 \mathrm{KDa}$ & anti-GSK-3 $\beta$ & $1: 2000$ & sc-9166 & Santa Cruz Biotechnol. \\
\hline pTau & $55 \mathrm{KDa}$ & mouse anti-Human PHF-Tau AT8 & $1: 2000$ & MN1020 & Pierce Biotechnology \\
\hline pTau & $55 \mathrm{KDa}$ & mouse anti-Human PHF-Tau AT100 & $1: 2000$ & MN1060 & Pierce Biotechnol. \\
\hline Tau & $55 \mathrm{KDa}$ & mouse anti-Tau & $1: 2000$ & MA1-38710 & Pierce Biotechnolog \\
\hline Pro-caspase & $949 \mathrm{KDa}$ & rabbit anti-caspase 9 (mouse spec.) & $1: 2000$ & 9504 & Cell Signaling Technol. \\
\hline Bax & $20 \mathrm{KDa}$ & rabbit anti-Bax & $1: 2000$ & 2772 & Cell Signaling Technol. \\
\hline \multirow[t]{2}{*}{$\mathrm{Bcl}-2$} & $26 \mathrm{Kda}$ & rabbit anti-Bcl-2 & & & \\
\hline & & (D17C4; mouse preferred) & $1: 2000$ & 3498 & Cell Signaling Technol. \\
\hline$\beta$ Tub & $49 \mathrm{KDa}$ & mouse monoclonal anti- $\beta$-Tubulin & $1: 5000$ & T4026 & Sigma-Aldrich \\
\hline \multicolumn{6}{|c|}{ Secondary antibodies } \\
\hline $\lg G$ & goat anti- & -rabbit lgG peroxidase conjugate & $1: 2000$ & \#A6154 & Sigma-Aldrich \\
\hline $\lg G$ & goat anti- & -mouse lgG peroxidase conjugate & $1: 2000-5000$ & \#A4416 & Sigma-Aldrich \\
\hline
\end{tabular}




\section{Figure legends}

Figure 1 Experimental protocol. Abbreviations: ICV, intracerebroventricular injection; YMT, Y-maze test; ST-PA, step-through passive avoidance; Sacrf., sacrifice of the animals and brain dissection; WMT, wtater-maze test; LPO, lipid peroxidation; DCF, ROS determination by DCF fluorescence.

Figure $2 \quad$ L41 prevented spatial working and contextual long-term memory impairments induced by $A \beta_{25-35}$ injection. Mice were administered i.c.v. with Sc. $A \beta$ or $A \beta_{25-35}$ peptide (9 $\mathrm{nmol})$ and vehicle or $\mathrm{L} 41(0.4,1.2$, or $4 \mu \mathrm{g} /$ mouse $)$. At day 7 , they were tested for spontaneous alternation: alternation percentage (a) and number of arm entries (b). At days 8-9, mice were tested for passive avoidance response: step-through latency (c) and escape latency (d). $\mathrm{n}=16-17$ per group. ANOVA: $F_{(4,79)}=6.29, \mathrm{p}<0.001$ in $(\mathrm{a}), F_{(4,79)}=0.42, \mathrm{p}>$ 0.05 in (b); $H=15.0, \mathrm{p}<0.01$ in (c); $H=5.12, \mathrm{p}<0.05$ in (d). ${ }^{*} \mathrm{p}<0.05 ;{ }^{* *} \mathrm{p}<0.01$ vs. Sc. $A \beta / V ; \# p<0.05 ; \# \# p<0.01$ vs. $A \beta_{25-35} / V ;$ Dunnett's test in (a), Dunn's test in (c, d).

Figure $3 \quad L 41$ prevented $A \beta_{25-35}$-induced learning impairments in the water-maze test. Mice were administered i.c.v. with Sc. $A \beta$ or $A \beta_{25-35}$ peptide $(9 \mathrm{nmol})$ and vehicle or $L 41$ (4 $\mu \mathrm{g})$. Place learning was assessed after 7 days: acquisition profiles $(a, b)$ and the time spent in the $T$ quadrant (c) and swimming speed (d) during the probe test. $\mathrm{n}=12$ per group. Repeated-measure non-parametric Friedman ANOVA: $F r=23.6, p<0.001$ for Sc.AB/Vtreated group; $F r=10.6, p>0.05$ for $A \beta_{235-35} / \mathrm{V}$-treated group in (a); $F r=24.7, p<0.001$ for $\mathrm{A} \beta_{235-35} / \mathrm{L} 41$-treated group in (b); $F_{(2,35)}=1.23, \mathrm{p}>0.05$ in (d). ${ }^{* *} \mathrm{p}<0.01 \mathrm{vs}$. Sc.AB/V at the same trial; $\# \mathrm{p}<0.05 ; \# \# \mathrm{p}<0.01$ vs. $A \beta_{25-35} / \mathrm{V}$ at the same trial; Mann-Whitney's test in (a, b). ${ }^{*} p<0.05 ;{ }^{* *} p<0.01 v s$. hazard level (15 s), one-column $t$-test in (c).

Figure $4 \quad L 41$ prevented $A \beta_{25-35}$-induced oxidative stress in hippocampus. Oxidative stress was assessed $1,3,5$ and 7 days after $A \beta_{25-35}$ injection in mouse hippocampus by 
measuring lipid peroxidation (a) and ROS accumulation using DCF fluorescence (c). The effect of $L 41$, at the dose of $4 \mu \mathrm{g}$, on $A \beta_{25-35}$-induced lipid peroxidation (b) and ROS accumulation (DCF) (d) was then assessed in the mouse hippocampus 7 days after coinjection. ${ }^{* *} p<0.01,{ }^{* * *} p<0.001$ vs. Sc.A $A$ control group on the same day; $t$-test, $n=6$ per group in (a), $\mathrm{n}=4-5$ in (c). ANOVA: $F_{(3,20)}=4.79, \mathrm{p}<0.05, \mathrm{n}=6$ per group in $(\mathrm{b}) ; F_{(3,32)}=$ $4.10, p<0.05 n=8-10$ in (d); ${ }^{*} p<0.05$ vs. Sc.A $/$ - -treated group; $\# \# p<0.01$ vs. $A \beta_{25-35} / \mathrm{V}$ treated group, Dunnett's test.

Figure $5 \quad L 41$ prevents $A \beta_{25-35}$-induced activation of kinases involved in Tau phosphorylation. Mice were administered i.c.v. with Sc.A $\beta$ or $A \beta_{25-35}$ peptide and sacrificed 1, 3, 5, 7 days after injection. The time-course of phosphorylation was determined for Akt on $\operatorname{Ser}^{473}$ (a) and GSK-3ß on $\operatorname{Tyr}^{216}$ (c) and $\operatorname{Ser}^{9}$ (e) in the hippocampus of $A \beta_{25-35}$-treated mice. The effect of $L 41,4 \mu \mathrm{g}$, was then examined on $A \beta_{25-35}$-induced decrease in $P\left(\mathrm{Ser}^{473}\right) A k t / A k t$

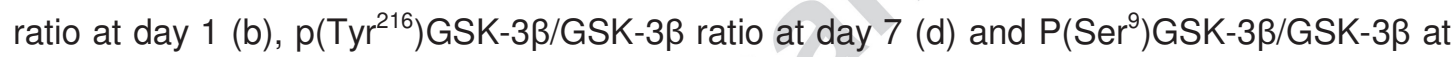
day 3 (f). Typical blots are shown under the graphs; the order of the experimental group is the same as described for the graph. ${ }^{*} p<0.05,{ }^{* *} p<0.01,{ }^{* * *} p<0.001$ vs. Sc.A $\beta$ control group on the same day; $t$-test, $n=8-14$ per group in (a), $n=9-14$ in (c), $n=6-8$ in (e). ANOVA: $F_{(2,33)}=18.3, \mathrm{p}<0.0001, \mathrm{n}=11-13$ per group in $(\mathrm{b}) ; F_{(3,38)}=10.75, \mathrm{p}<0.0001, \mathrm{n}=$ $4-14$ in (d); $F_{(3,23)}=1.90, \mathrm{p}>0.05, \mathrm{n}=5-8$ in (f); ${ }^{*} p<0.05,{ }^{* *} p<0.01,{ }^{* \star *} p<0.001$ vs. Sc. $A \beta / V$-treated group; $\# p<0.05, \# \# p<0.01$ vs. $A \beta_{25-35} / V$-treated group, Dunnett's test.

Figure $6 \quad L 41$ prevented the $A \beta_{25-35}$-induced phosphorylation of Tau. Mice were administered i.c.v. with Sc.A $\beta$ or $A \beta_{25-35}$ peptide and $L 41(4 \mu \mathrm{g})$ and sacrificed 7 days after injection. Tau phosphorylation was assessed by western blotting using AT8 $\left(\mathrm{Ser}^{202} / \mathrm{Thr}^{205}\right)$ (a) and AT100 $\left(\mathrm{Ser}^{212} / \mathrm{Thr}^{214}\right)$ antibodies (b). Typical blots are shown in (c). ANOVA: $F_{(3,39)}=$ 17.6, $\mathrm{p}<0.001, \mathrm{n}=10-12$ in (a); $F_{(3,66)}=1.07, \mathrm{p}>0.05, \mathrm{n}=15-20$, in $(\mathrm{b}) ;{ }^{*} \mathrm{p}<0.05,{ }^{* *} \mathrm{p}<$ 0.01 vs. Sc. $A \beta / V$-treated group; $\# p<0.05$ vs. $A \beta_{25-35} / V$-treated group; Dunnett's test. 
Figure $7 \quad L 41$ prevented $A \beta_{25-35}$ induction of pro-apoptotic pathway. Mice were administered i.c.v. with Sc.A $\beta$ or $A \beta_{25-35}$ peptide $(9 \mathrm{nmol})$ and sacrificed $1,3,5$ and 7 days after injection. The level of Bax expression was assessed by western blot in hippocampus (a). The effect of $L 41(4 \mu \mathrm{g})$ on $A \beta_{25-35}$-induction of pro-apoptotic markers was examined in the mouse hippocampus 7 days after co-injection: $\mathrm{Bax}(\mathrm{b}), \mathrm{Bcl}-2$ (c), Bax/Bcl-2 ratio (d) and pro-caspase-9 (e). Typical blots are shown in (f, g). ${ }^{*} p<0.05$ vs. Sc.A $\beta$ control group on the same day; $t$-test, $\mathrm{n}=6-8$ per group in (a). ANOVA: $F_{(3,21)}=4.81, \mathrm{p}<0.01, \mathrm{n}=6-7$ in (b); $F_{(3,42)}$ $=2.87, \mathrm{p}<0.05, \mathrm{n}=8-15$ in (c); $F_{(3,44)}=5.46, \mathrm{p}<0.01, \mathrm{n}=11-13$ in $(\mathrm{d}) ; F_{(3,41)}=3.72, \mathrm{p}<$ $0.05, n=11-12$ in (e); ${ }^{*} p<0.05,{ }^{* *} p<0.01$ vs. Sc.A $\beta / V$-treated group; $\# p<0.05$ vs. $A \beta_{25-}$ ${ }_{35} / \mathrm{V}$-treated group; Dunnett's test.

Figure $8 \quad$ L41 reverses synaptic markers deficit in the hippocampus induced by $A \beta_{25-35}$ injection. Mice were administered i.c.v. with Sc.A $\beta$ or $A \beta_{25-35}$ peptide $(9 \mathrm{nmol})$ and $L 41(4 \mu \mathrm{g})$ and sacrificed 7 days after injection. The levels of synaptic markers were assessed in hippocampus by ELISA: Arc (a), Egr1 (b), PSD95 (c) and synaptophysin (d). ANOVA: $F_{(3,28)}=$ $3.61, \mathrm{p}<0.05, \mathrm{n}=6-9$ in $(\mathrm{a}) ; F_{(3,30)}=3.00, \mathrm{p}<0.05, \mathrm{n}=8-10$ in $(\mathrm{b}) ; F_{(3,28)}=3.71, \mathrm{p}<0.05, \mathrm{n}$ $=6-10$, in (c); $F_{(3,28)}=3.59, p<0.05, n=7-9$ in (d); ${ }^{*} p<0.05$ vs. Sc.A $/ V$-treated group; \# $p$ $<0.05$ vs. $A \beta_{25-35} / \mathrm{V}$-treated group; Dunnett's test. 


\section{References}

Adayev, T., Wegiel, J., Hwang, Y.W., 2011. Harmine is an ATP-competitive inhibitor for dualspecificity tyrosine phosphorylation-regulated kinase 1A (Dyrk1A). Arch. Biochem. Biophys. 507, 212-218.

Aplin, A.E., Gibb, G.M., Jacobsen, J.S., Gallo, J.M., Anderton, B.H., 1996. In vitro phosphorylation of the cytoplasmic domain of the amyloid precursor protein by glycogen synthase kinase-3ß. J. Neurochem. 67, 699-707.

Blalock, E.M., Chen, K.C., Sharrow, K., Herman, J.P., Porter, N.M., Foster, T.C., Landfield, P.W., 2003. Gene microarrays in hippocampal aging: statistical profiling identifies novel processes correlated with cognitive impairment. J. Neurosci. 23, 3807-3819.

Bloomer, W.A., VanDongen, H.M., VanDongen, A.M., 2008. Arc/Arg3.1 translation is controlled by convergent N-methyl-D-aspartate and Gs-coupled receptor signaling pathways. J. Biol. Chem. 283, 582-592.

Burgy, G., Tahtouh, T., Durieu, E., Foll-Josselin, B., Limanton, E., Meijer, L., Carreaux, F., Bazureau, J.P., 2013. Chemical synthesis and biological validation of immobilized protein kinase inhibitory Leucettines. Eur. J. Med. Chem. 62C, 728-737.

Choi, H.K., Chung, K.C., 2011. Dyrk1A positively stimulates ASK1-JNK signaling pathway during apoptotic cell death. Exp. Neurobiol. 20, 35-44.

de la Torre, R., Dierssen, M., 2012. Therapeutic approaches in the improvement of cognitive performance in Down syndrome: past, present, and future. Prog. Brain Res. 197, 1-14.

Debdab, M., Carreaux, F., Renault, S., Soundararajan, M., Fedorov, O., Filippakopoulos, P., Lozach, O., Babault, L., Tahtouh, T., Baratte, B., Ogawa, Y., Hagiwara, M., Eisenreich, A., Rauch, U., Knapp, S., Meijer, L., Bazureau, J.P., 2011. Leucettines, a class of potent inhibitors of cdc2-like kinases and dual specificity, tyrosine phosphorylation regulated kinases derived from the marine sponge leucettamine B: modulation of alternative pre-RNA splicing. J. Med. Chem. 54, 4172-4186. 
Dickey, C.A., Gordon, M.N., Mason, J.E., Wilson, N.J., Diamond, D.M., Guzowski, J.F., Morgan, D., 2004. Amyloid suppresses induction of genes critical for memory consolidation in APP + PS1 transgenic mice. J. Neurochem. 88, 434-442.

Fang, X., Yu, S.X., Lu, Y., Bast, R.C., Jr., Woodgett, J.R., Mills, G.B., 2000. Phosphorylation and inactivation of glycogen synthase kinase 3 by protein kinase A. Proc. Natl. Acad. Sci. USA 97, 11960-11965.

Ferrer, I., Barrachina, M., Puig, B., Martinez de Lagran, M., Marti, E., Avila, J., Dierssen, M., 2005. Constitutive Dyrk1A is abnormally expressed in Alzheimer disease, Down syndrome, Pick disease, and related transgenic models. Neurobiol. Dis. 20, 392-400.

Flaherty, D.B., Soria, J.P., Tomasiewicz, H.G., Wood, J.G., 2000. Phosphorylation of human tau protein by microtubule-associated kinases: GSK3 $\beta$ and cdk5 are key participants. J. Neurosci. Res. 62, 463-472.

Giovanni, A., Keramaris, E., Morris, E.J., Hou, S.T., O'Hare, M., Dyson, N., Robertson, G.S., Slack, R.S., Park, D.S., 2000. E2F1 mediates death of B-amyloid-treated cortical neurons in a manner independent of p53 and dependent on Bax and caspase 3. J. Biol. Chem. 275, 11553-11560.

Hu, S., Begum, A.N., Jones, M.R., Oh, M.S., Beech, W.K., Beech, B.H., Yang, F., Chen, P., Ubeda, O.J., Kim, P.C., Davies, P., Ma, Q., Cole, G.M., Frautschy, S.A., 2009. GSK3 inhibitors show benefits in an Alzheimer's disease (AD) model of neurodegeneration but adverse effects in control animals. Neurobiol Dis. 33, 193-206.

lijima, K., Ando, K., Takeda, S., Satoh, Y., Seki, T., Itohara, S., Greengard, P., Kirino, Y., Nairn, A.C., Suzuki, T., 2000. Neuron-specific phosphorylation of Alzheimer's $\beta$ amyloid precursor protein by cyclin-dependent kinase 5. J. Neurochem. 75, 1085-1091.

Iqbal, K., Gong, C.X., Liu, F., 2014. Microtubule-associated protein tau as a therapeutic target in Alzheimer's disease. Expert Opin Ther Targets. 18, 307-318.

Kaminsky, Y.G., Marlatt, M.W., Smith, M.A., Kosenko, E.A., 2010. Subcellular and metabolic examination of amyloid- $\beta$ peptides in Alzheimer disease pathogenesis: evidence for

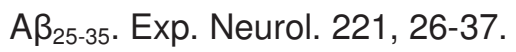


Kimura, R., Kamino, K., Yamamoto, M., Nuripa, A., Kida, T., Kazui, H., Hashimoto, R., Tanaka, T., Kudo, T., Yamagata, H., Tabara, Y., Miki, T., Akatsu, H., Kosaka, K., Funakoshi, E., Nishitomi, K., Sakaguchi, G., Kato, A., Hattori, H., Uema, T., Takeda, M., 2007. The DYRK1A gene, encoded in chromosome 21 Down syndrome critical region, bridges between $\beta$-amyloid production and tau phosphorylation in Alzheimer disease. Human Mol. Genet. 16, 15-23.

Kitamura, Y., Shimohama, S., Kamoshima, W., Ota, T., Matsuoka, Y., Nomura, Y., Smith, M.A., Perry, G., Whitehouse, P.J., Taniguchi, T., 1998. Alteration of proteins regulating apoptosis, Bcl-2, Bcl-x, Bax, Bak, Bad, ICH-1 and CPP32, in Alzheimer's disease. Brain Res. 780, 260-269.

Kudo, W., Lee, H.P., Smith, M.A., Zhu, X., Matsuyama, S., Lee, H.G., 2012. Inhibition of Bax protects neuronal cells from oligomeric $A \beta$ neurotoxicity. Cell Death Dis. 3, e309.

Laguna, A., Barallobre, M.J., Marchena, M.Á., Mateus, C., Ramírez, E., Martínez-Cue, C., Delabar, J.M., Castelo-Branco, M., de la Villa, P., Arbonés, M.L., 2013. Triplication of DYRK1A causes retinal structural and functional alterations in Down syndrome. Hum Mol Genet. 22, 2775-2784.

Lahmy, V., Meunier, J., Malmstrom, S., Naert, G., Givalois, L., Kim, S.H., Villard, V., Vamvakides, A., Maurice, T., 2013. Blockade of Tau hyperphosphorylation and $A \beta$ generation by the aminotetrahydrofuran derivative ANAVEX2-73, a mixed muscarinic and $\sigma_{1}$ receptor agonist, in a nontransgenic mouse model of Alzheimer's disease. Neuropsychopharmacology 38, 1706-1723.

Lau, K.F., Howlett, D.R., Kesavapany, S., Standen, C.L., Dingwall, C., McLoughlin, D.M., Miller, C.C., 2002. Cyclin-dependent kinase-5/p35 phosphorylates presenilin 1 to regulate carboxy-terminal fragment stability. Mol. Cell. Neurosci. 20, 13-20.

Liu, F., Liang, Z., Wegiel, J., Hwang, Y.W., Iqbal, K., Grundke-lqbal, I., Ramakrishna, N., Gong, C.X., 2008. Overexpression of Dyrk1A contributes to neurofibrillary degeneration in Down syndrome. Faseb J. 22, 3224-3233.

Ma, T., Klann, E., 2011. Amyloid $\beta$ : linking synaptic plasticity failure to memory disruption in Alzheimer's disease. J. Neurochem. 120 Suppl 1, 140-148. 
Malinow, R., Malenka, R.C., 2002. AMPA receptor trafficking and synaptic plasticity. Ann. Rev. Neurosci. 25, 103-126.

Mandel, S.A., Amit, T., Kalfon, L., Reznichenko, L., Weinreb, O., Youdim, M.B., 2008. Cell signaling pathways and iron chelation in the neurorestorative activity of green tea polyphenols: special reference to epigallocatechin gallate (EGCG). J. Alzheimers Dis. $15,211-222$.

Maurice, T., Lockhart, B.P., Privat, A., 1996. Amnesia induced in mice by centrally administered $\beta$-amyloid peptides involves cholinergic dysfunction. Brain Res. 706, 181193.

Medina, M., Garrido, J.J., Wandosell, F.G., 2011. Modulation of GSK-3 as a therapeutic strategy on Tau pathologies. Frontiers Mol. Neurosci. 4, 24.

Morfini, G., Szebenyi, G., Brown, H., Pant, H.C., Pigino, G., DeBoer, S., Beffert, U., Brady, S.T., 2004. A novel CDK5-dependent pathway for regulating GSK3 activity and kinesindriven motility in neurons. EMBO J. 23, 2235-2245.

Naert, G., Rivest, S., 2012. Age-related changes in synaptic markers and monocyte subsets link the cognitive decline of APP(Swe)/PS1 mice. Front. Cell. Neurosci. 6, 51.

Ngok-Ngam, P., Watcharasit, P., Thiantanawat, A., Satayavivad, J., 2013. Pharmacological inhibition of GSK3 attenuates DNA damage-induced apoptosis via reduction of p53 mitochondrial translocation and Bax oligomerization in neuroblastoma SH-SY5Y cells. Cell. Mol. Biol. Lett. 18, 58-74.

Reus, G.Z., Stringari, R.B., de Souza, B., Petronilho, F., Dal-Pizzol, F., Hallak, J.E., Zuardi, A.W., Crippa, J.A., Quevedo, J., 2010. Harmine and imipramine promote antioxidant activities in prefrontal cortex and hippocampus. Oxid. Med. Cell. Longev. 3, 325-331.

Ryder, J., Su, Y., Liu, F., Li, B., Zhou, Y., Ni, B., 2003. Divergent roles of GSK3 and CDK5 in APP processing. Biochem. Biophys. Res. Commun. 312, 922-929.

Ryoo, S.R., Cho, H.J., Lee, H.W., Jeong, H.K., Radnaabazar, C., Kim, Y.S., Kim, M.J., Son, M.Y., Seo, H., Chung, S.H., Song, W.J., 2008. Dual-specificity tyrosine(Y)phosphorylation regulated kinase 1A-mediated phosphorylation of amyloid precursor 
protein: evidence for a functional link between Down syndrome and Alzheimer's disease. J. Neurochem. 104, 1333-1344.

Ryu, Y.S., Park, S.Y., Jung, M.S., Yoon, S.H., Kwen, M.Y., Lee, S.Y., Choi, S.H., Radnaabazar, C., Kim, M.K., Kim, H., Kim, K., Song, W.J., Chung, S.H., 2010. Dyrk1Amediated phosphorylation of Presenilin 1: a functional link between Down syndrome and Alzheimer's disease. J. Neurochem. 115, 574-584.

Selkoe, D.J., 2002. Alzheimer's disease is a synaptic failure. Science 298, 789-791.

Sengupta, A., Wu, Q., Grundke-lqbal, I., Iqbal, K., Singh, T.J., 1997. Potentiation of GSK-3catalyzed Alzheimer-like phosphorylation of human tau by cdk5. Mol. Cell. Biochem. 167, 99-105.

Sheppard, O., Plattner, F., Rubin, A., Slender, A., Linehan, J.M., Brandner, S., Tybulewicz, V.L., Fisher, E.M., Wiseman, F.K., 2012. Altered regulation of tau phosphorylation in a mouse model of down syndrome aging. Neurobiol. Aging 33, 828.e31-44.

Shindoh, N., Kudoh, J., Maeda, H., Yamaki, A., Minoshima, S., Shimizu, Y., Shimizu, N., 1996. Cloning of a human homolog of the Drosophila minibrain/rat Dyrk gene from "the Down syndrome critical region" of chromosome 21. Biochem. Biophys. Res. Commun. 225, 92-99.

Song, W.J., Sternberg, L.R., Kasten-Sportès, C., Keuren, M.L., Chung, S.H., Slack, A.C., Miller, D.E., Glover, T.W., Chiang, P.W., Lou, L., Kurnit, D.M., 1996. Isolation of human and murine homologues of the Drosophila minibrain gene: human homologue maps to 21q22.2 in the Down syndrome "critical region". Genomics. , 38, 331-339.

Tahtouh, T., Elkins, J.M., Filippakopoulos, P., Soundararajan, M., Burgy, G., Durieu, E., Cochet, C., Schmid, R.S., Lo, D.C., Delhommel, F., Oberholzer, A.E., Pearl, L.H., Carreaux, F., Bazureau, J.P., Knapp, S., Meijer, L., 2012. Selectivity, cocrystal structures, and neuroprotective properties of leucettines, a family of protein kinase inhibitors derived from the marine sponge alkaloid leucettamine B. J. Med. Chem. 55, 9312-9330.

Takashima, A., Honda, T., Yasutake, K., Michel, G., Murayama, O., Murayama, M., Ishiguro, K., Yamaguchi, H., 1998. Activation of tau protein kinase I/glycogen synthase kinase- 
$3 \beta$ by amyloid $\beta_{25-35}$ enhances phosphorylation of tau in hippocampal neurons. Neurosci. Res. 31, 317-323.

Tesco, G., Tanzi, R.E., 2000. GSK3 $\beta$ forms a tetrameric complex with endogenous PS1CTF/NTF and $\beta$-catenin. Effects of the D257/D385A and FAD-linked mutations. Ann. NY Acad. Sci. 920, 227-232.

Wegenast-Braun, B.M., Fulgencio Maisch, A., Eicke, D., Radde, R., Herzig, M.C., Staufenbiel, M., Jucker, M., Calhoun, M.E., 2009. Independent effects of intra- and extracellular $A \beta$ on learning-related gene expression. Am. J. Pathol. 175, 271-282.

Woods, Y.L., Cohen, P., Becker, W., Jakes, R., Goedert, M., Wang, X., Proud, C.G., 2001. The kinase DYRK phosphorylates protein-synthesis initiation factor elF2B $\varepsilon$ at $\operatorname{Ser}^{539}$ and the microtubule-associated protein tau at $\mathrm{Thr}^{212}$ : potential role for DYRK as a glycogen synthase kinase 3-priming kinase. Biochem. J. 355, 609-615.

Xiao, B., Tu, J.C., Petralia, R.S., Yuan, J.P., Doan, A., Breder, C.D., Ruggiero, A., Lanahan, A.A., Wenthold, R.J., Worley, P.F., 1998. Homer regulates the association of group 1 metabotropic glutamate receptors with multivalent complexes of homer-related, synaptic proteins. Neuron 21, 707-716.

Zussy, C., Brureau, A., Delair, B., Marchal, S., Keller, E., Ixart, G., Naert, G., Meunier, J., Chevallier, N., Maurice, T., Givalois, L., 2011. Time-course and regional analyses of the physiopathological changes induced after cerebral injection of an amyloid- $\beta$ fragment in rats. Am. J. Pathol. 179, 315-334.

Zussy, C., Brureau, A., Keller, E., Marchal, S., Blayo, C., Delair, B., Ixart, G., Maurice, T., Givalois, L., 2013. Alzheimer's disease related markers, cellular toxicity and behavioral deficits induced six weeks after oligomeric amyloid- $\beta$ peptide injection in rats. PLoS ONE 8(1): e53117. 


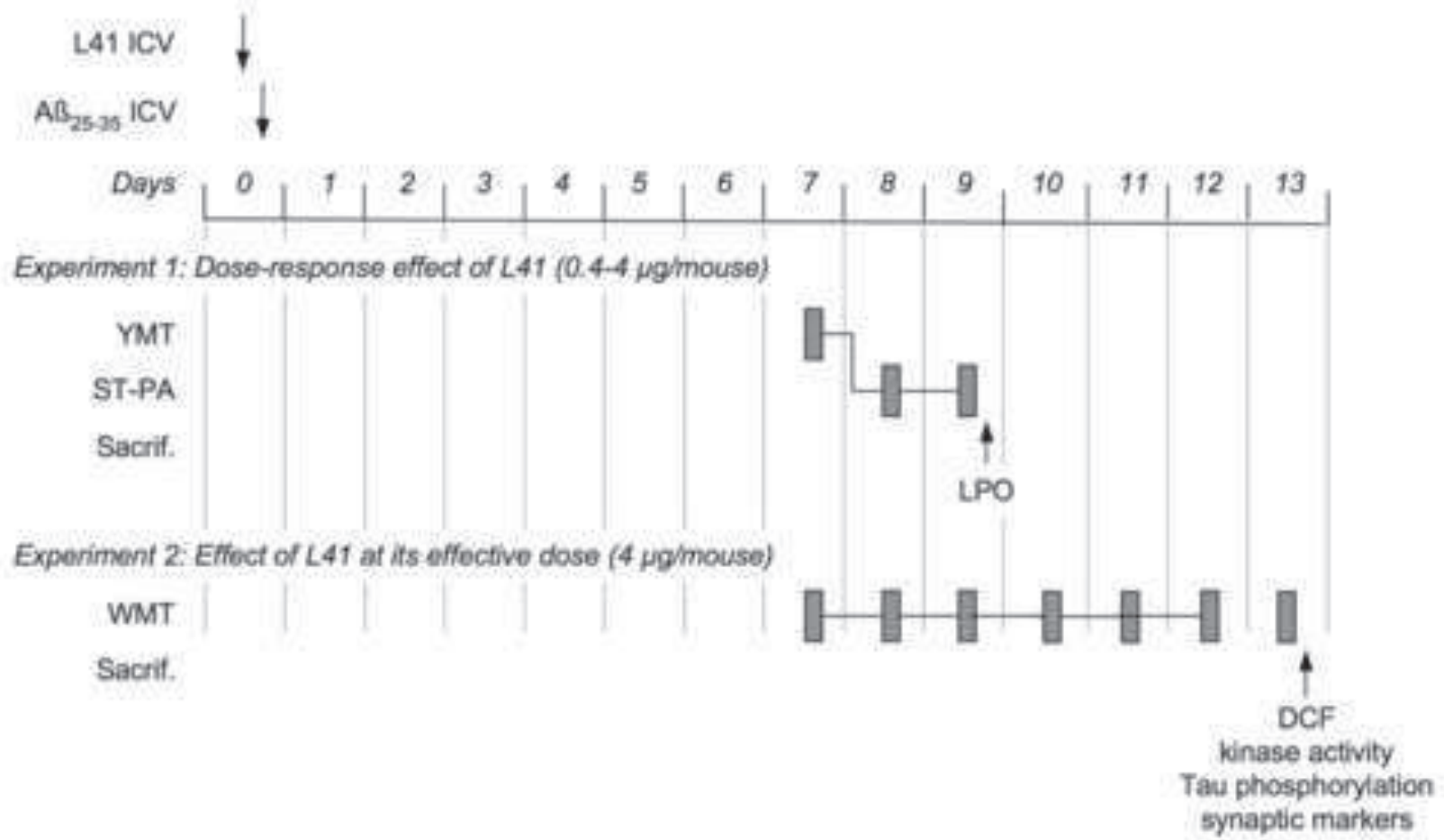




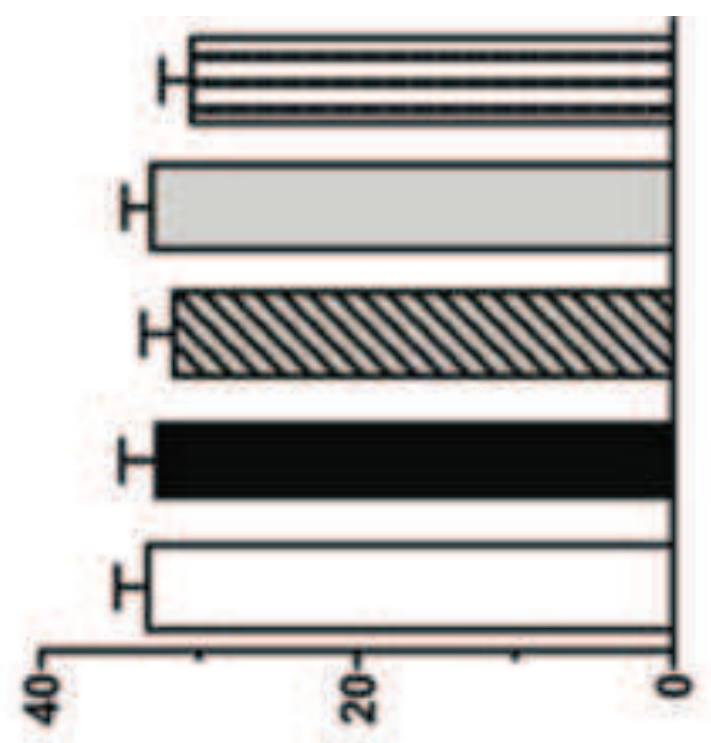

¿ selnue uue jo səqunN

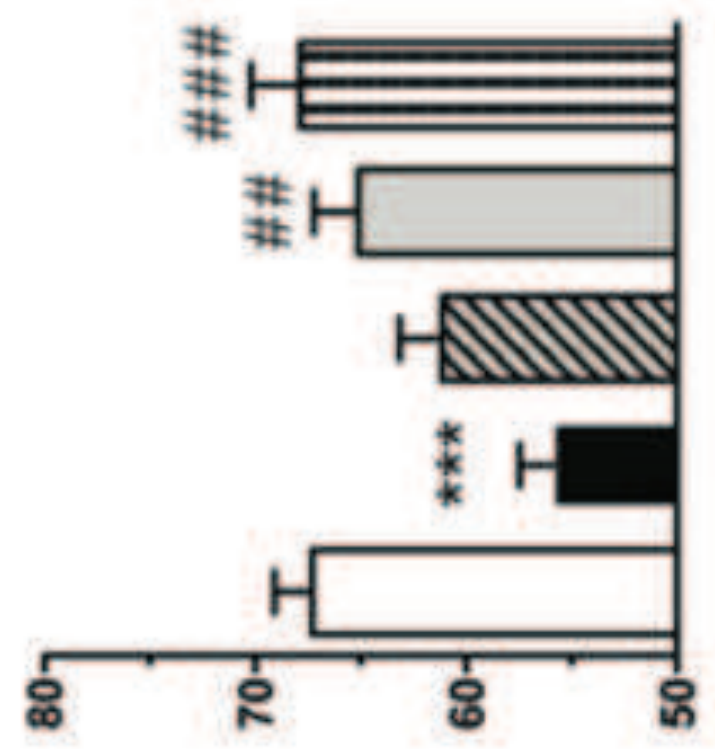

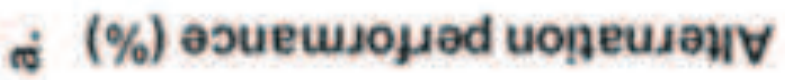

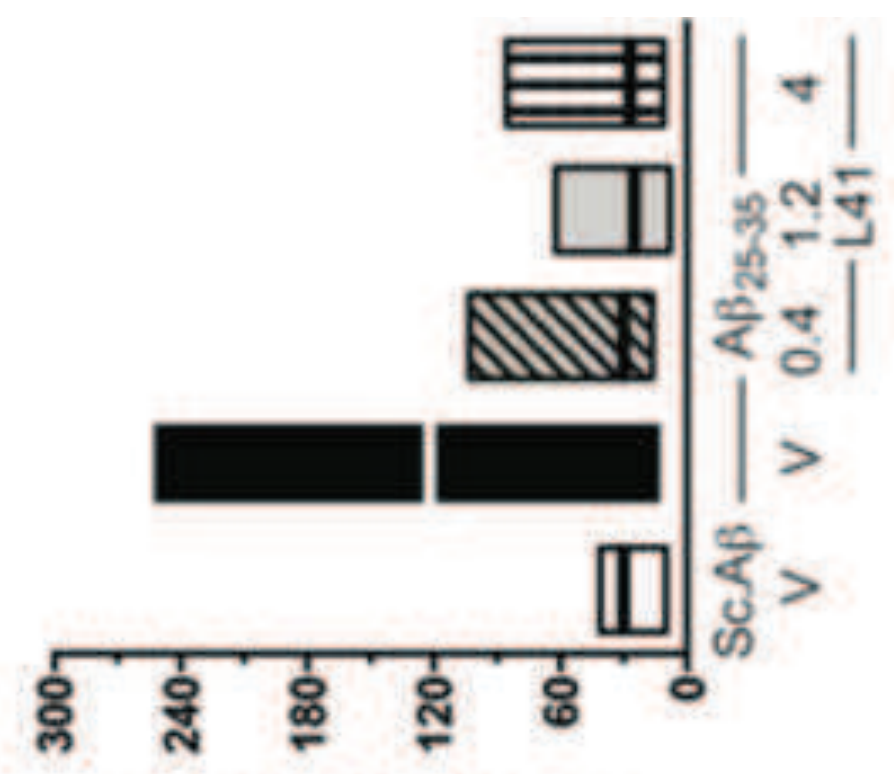

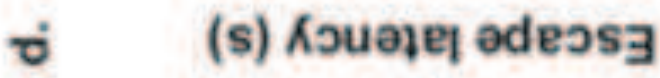
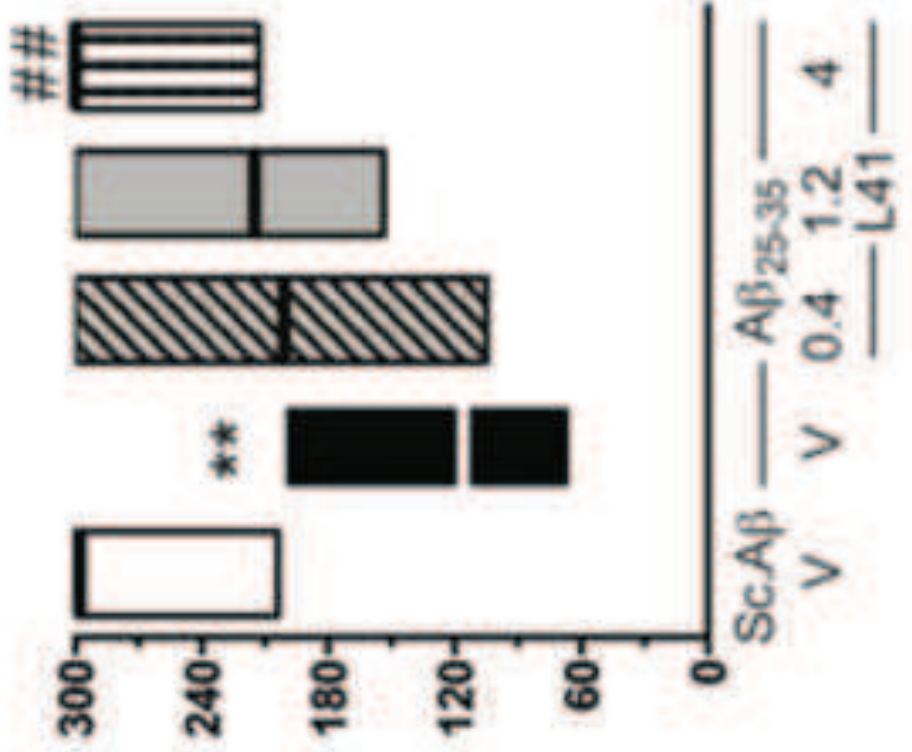

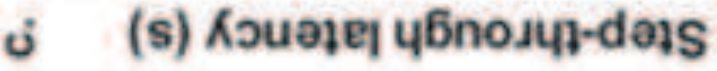




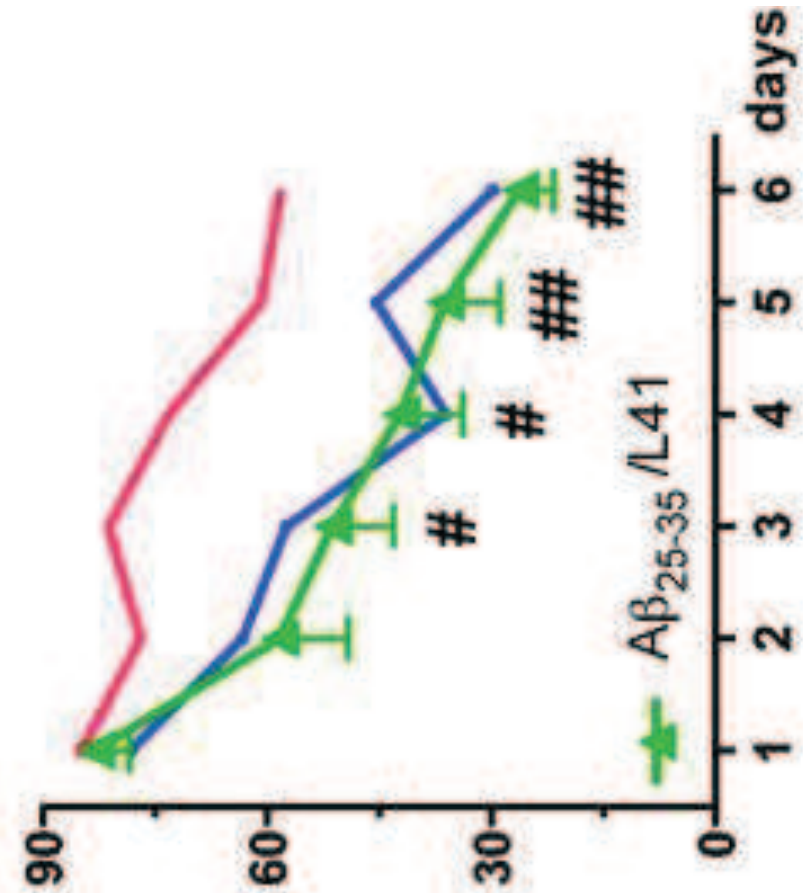

อ

(s) uoṇe..np bu!̣uw!̣s

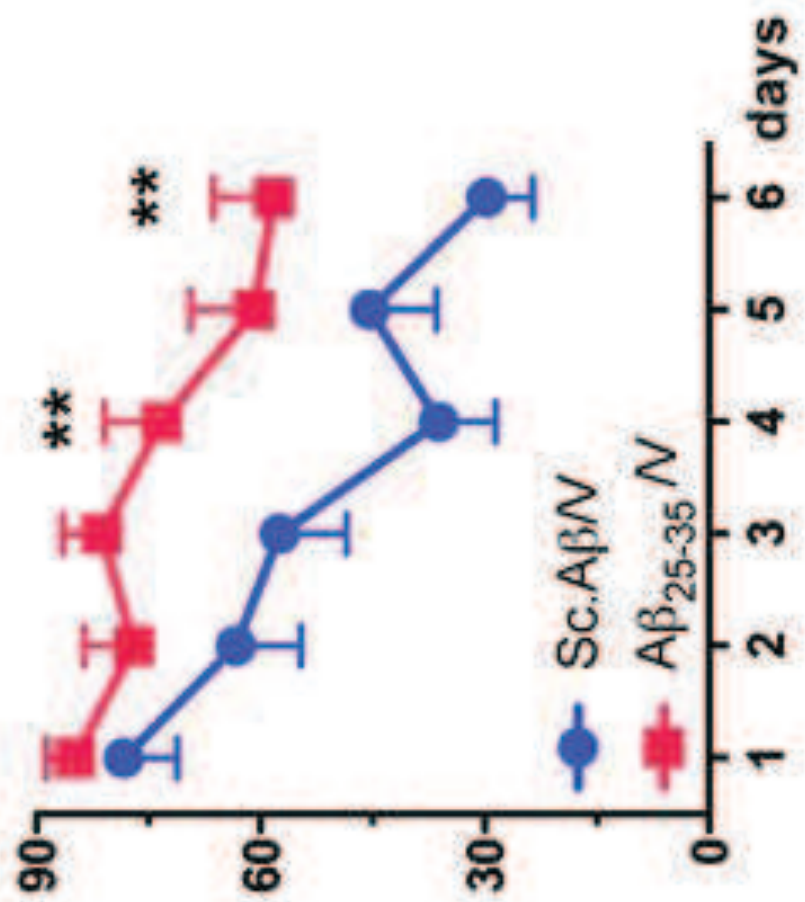

ก่

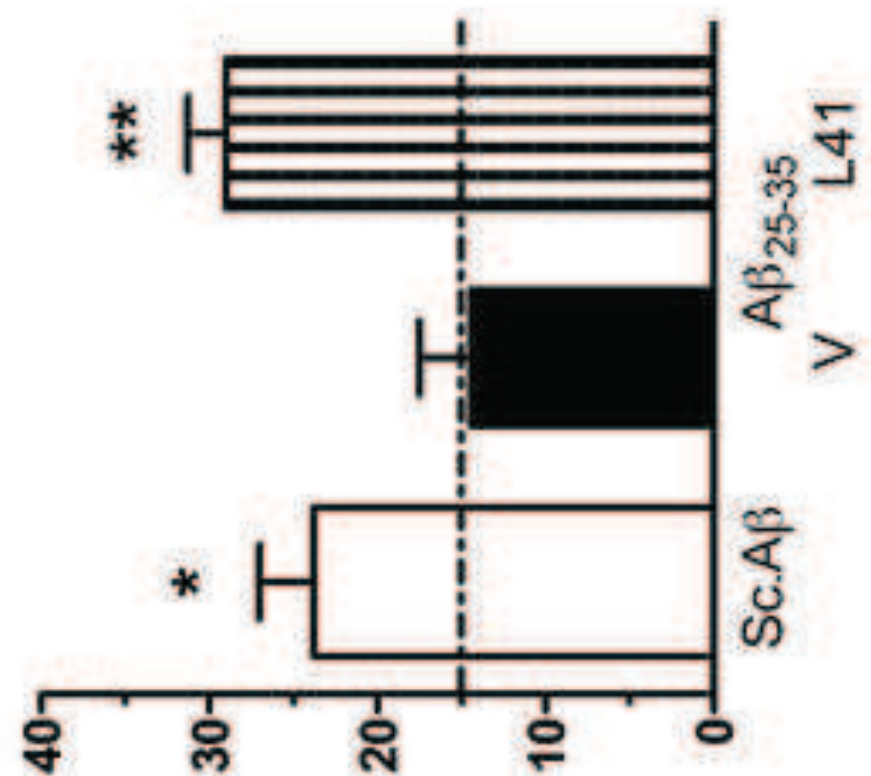

ن (s) ұue.penb $\perp$ u! әu! $\perp$
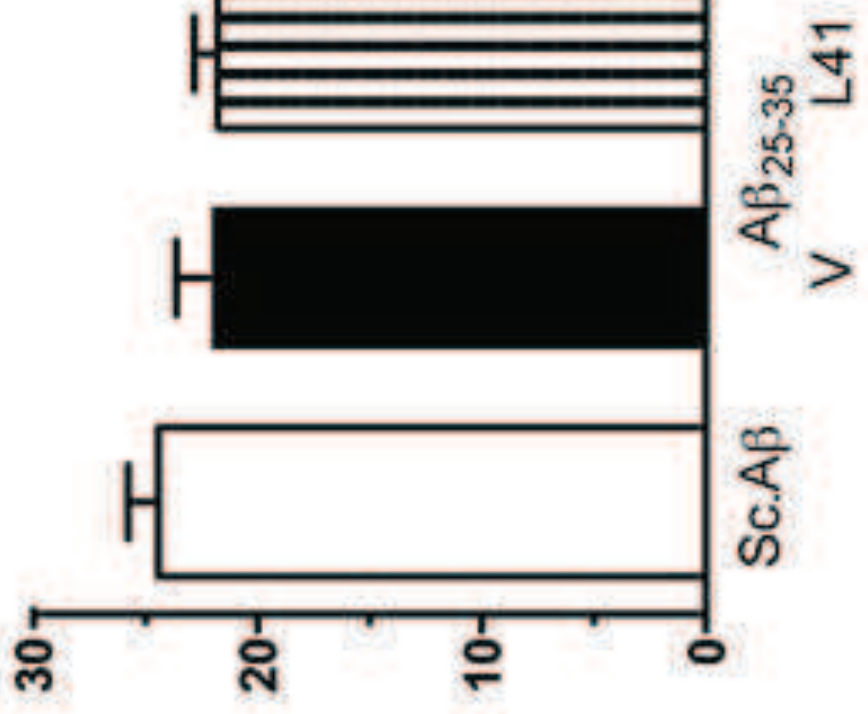

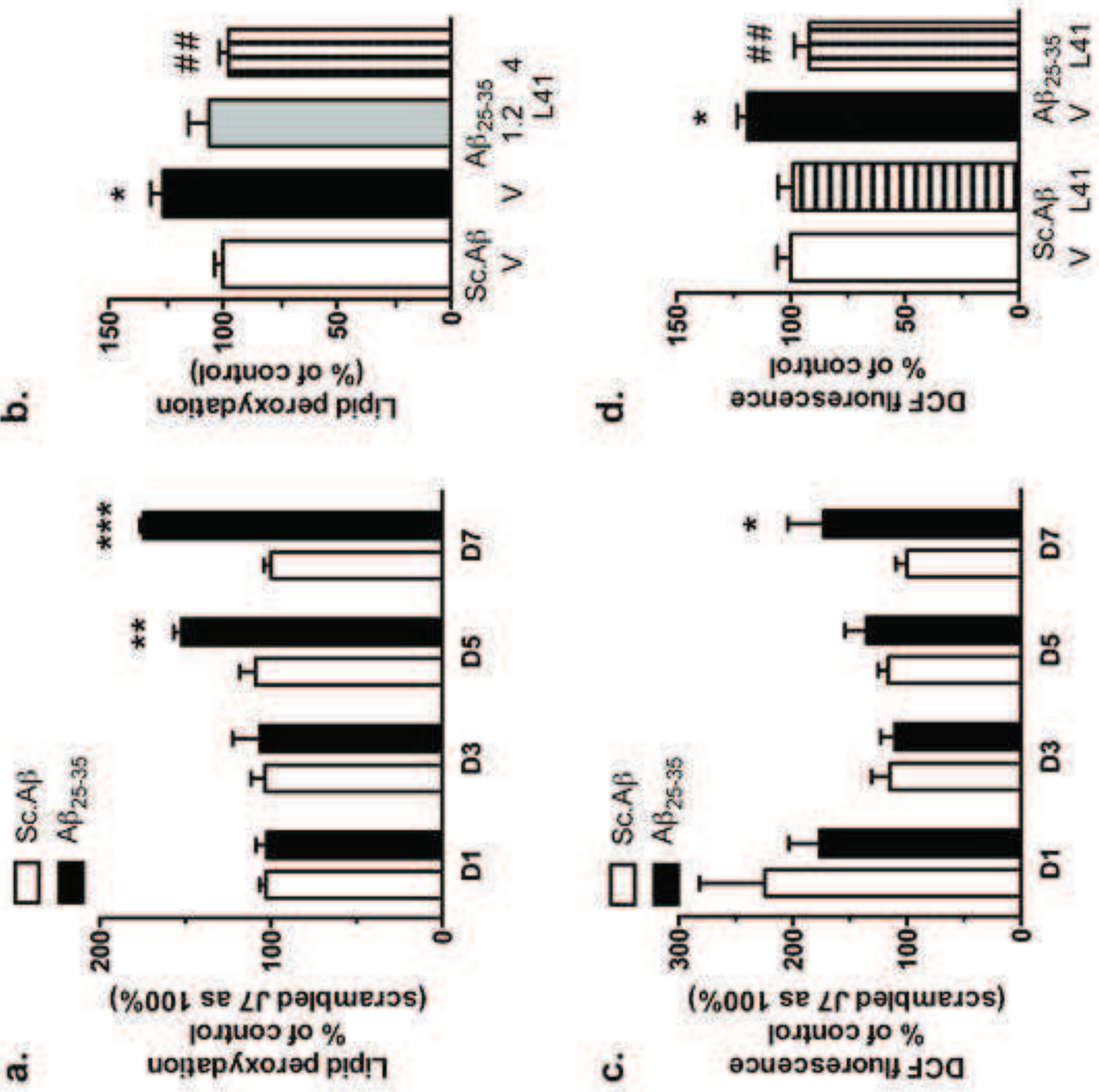
a.

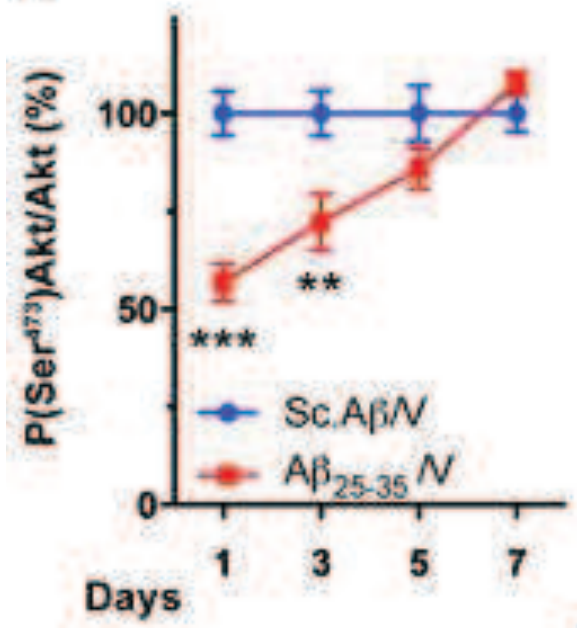

b.

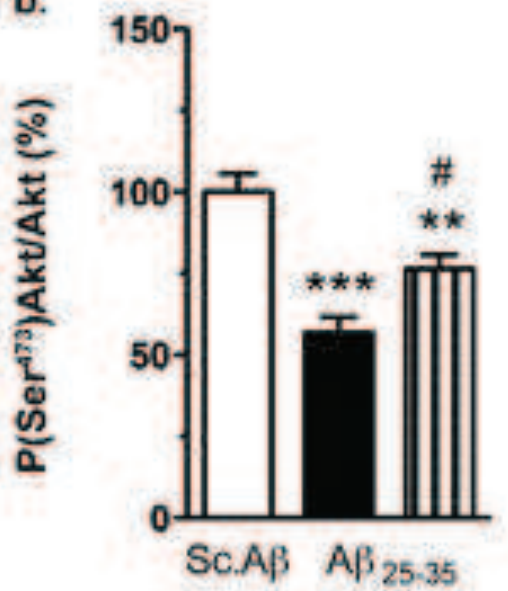

$\mathrm{P}\left(\mathrm{Ser}^{473}\right)$ Akt

Akt

c.

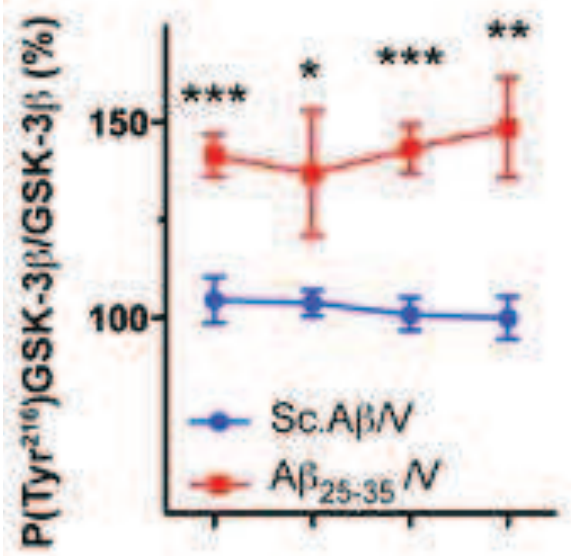

e.

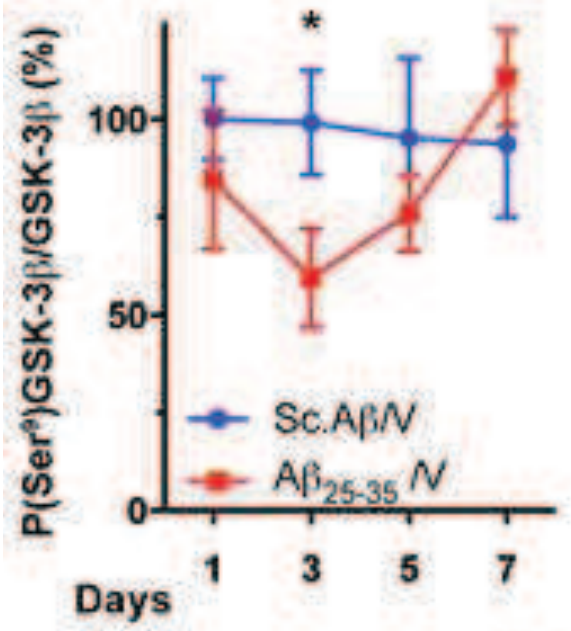

d.

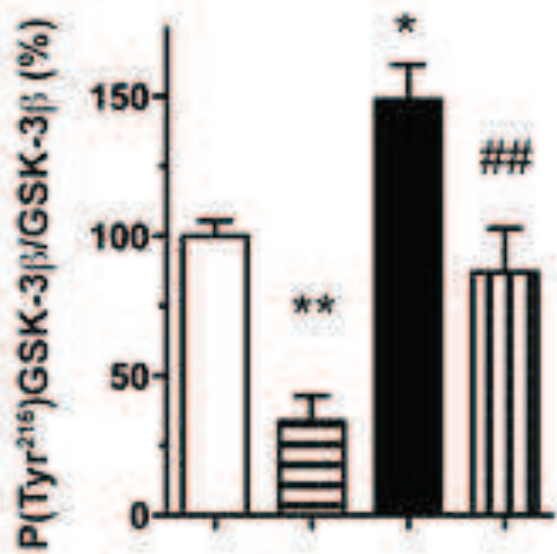

f.

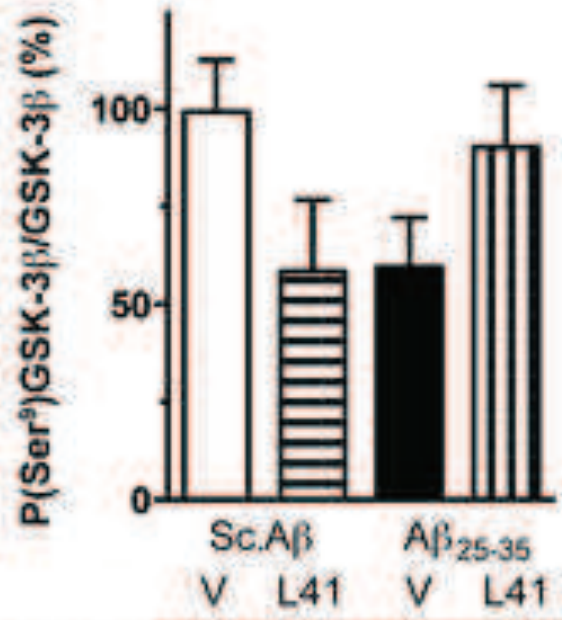

P(Tyr $\left.{ }^{216}\right)$ GSK-3p P(Ser ${ }^{\circ}$ GSK-3B 
a.

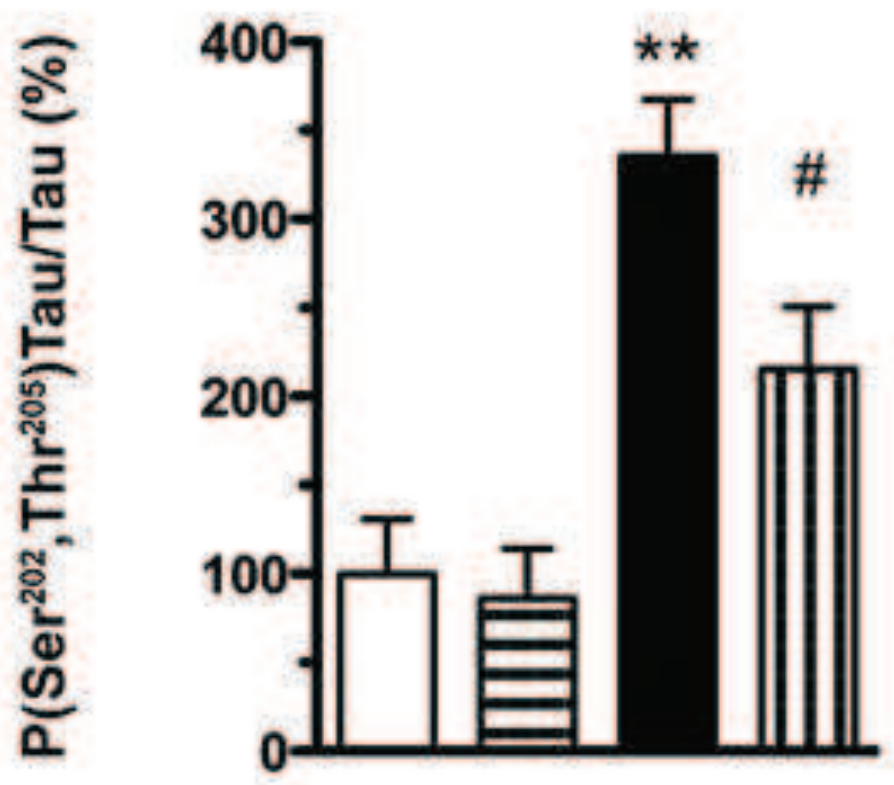

b.

c.
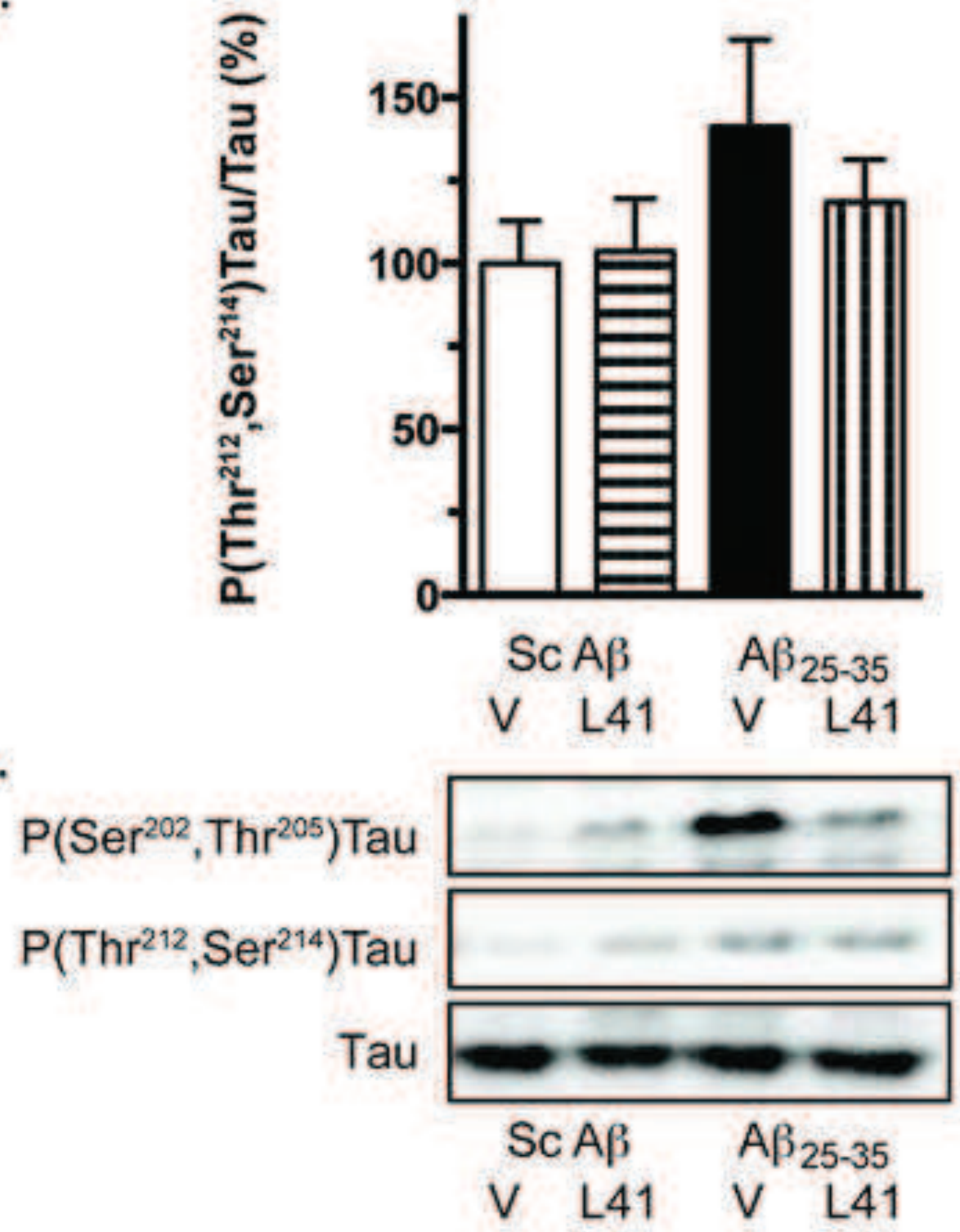


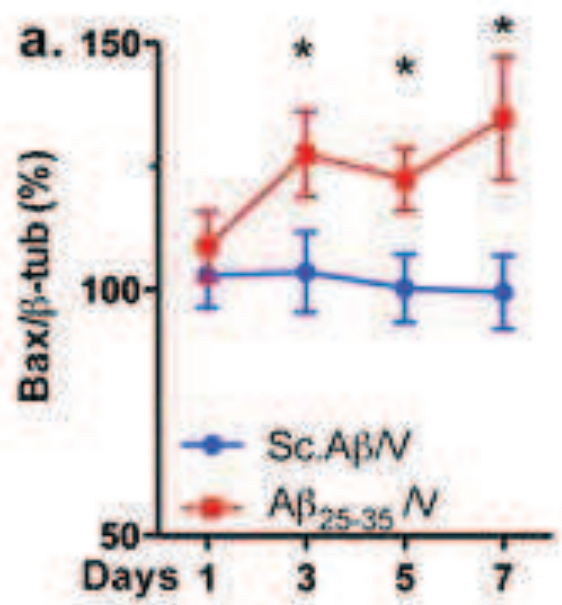

b.

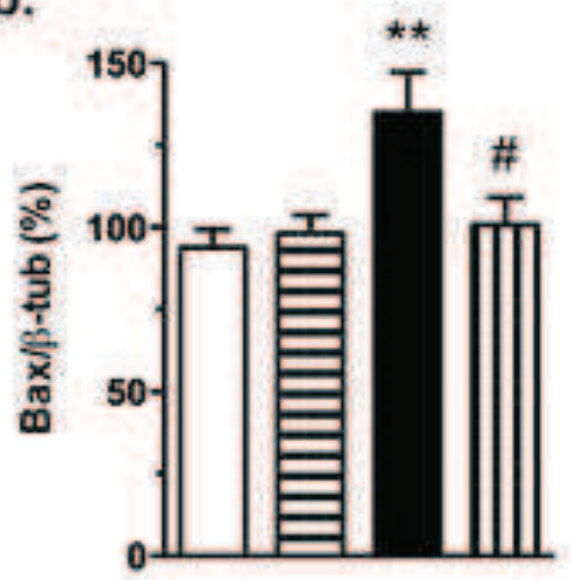

d.

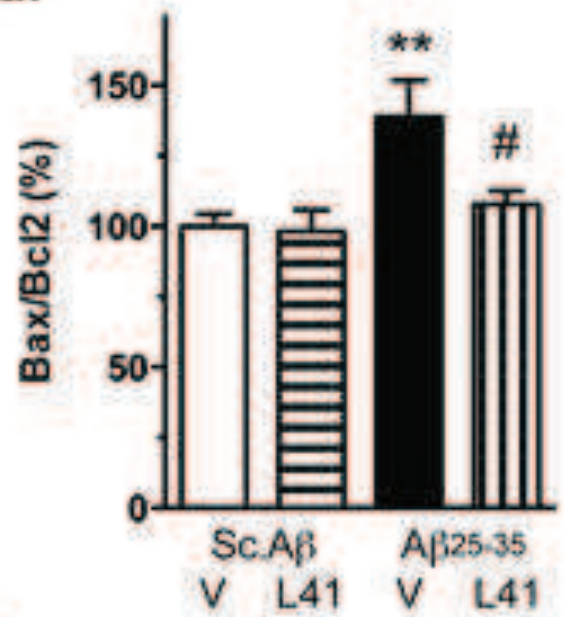

f.

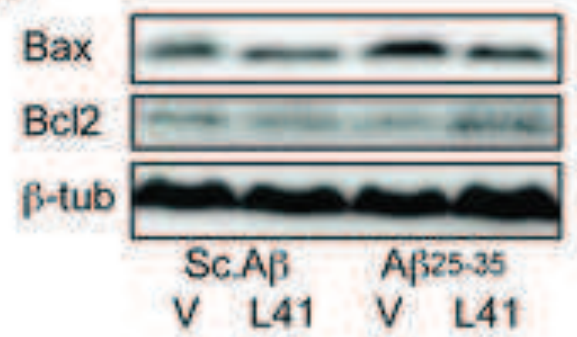

c.

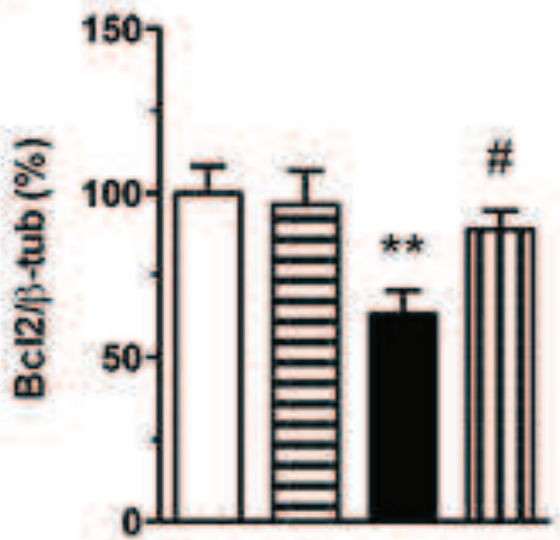

e.

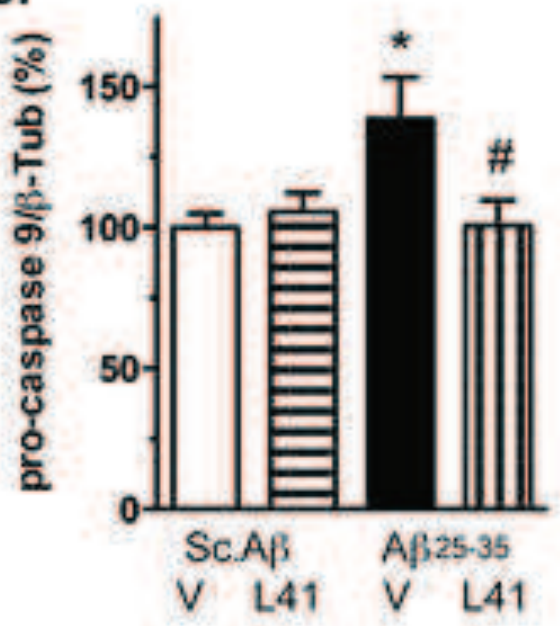

g.

pro-C9 B-tub

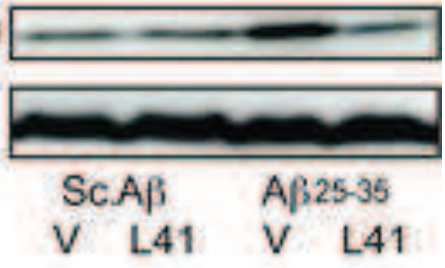




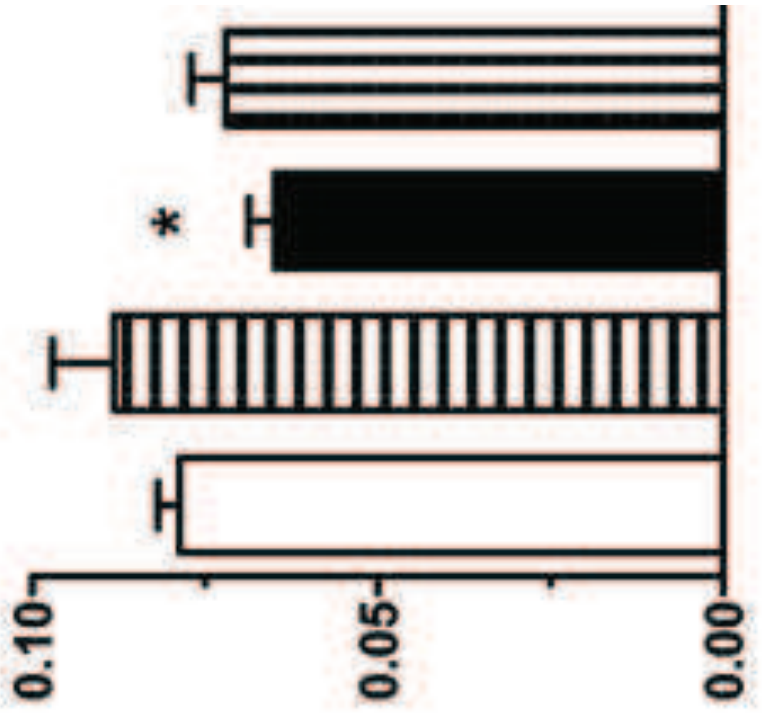

snduesodd!̣ 4 fo $6 u / 6 u$ .16

อ

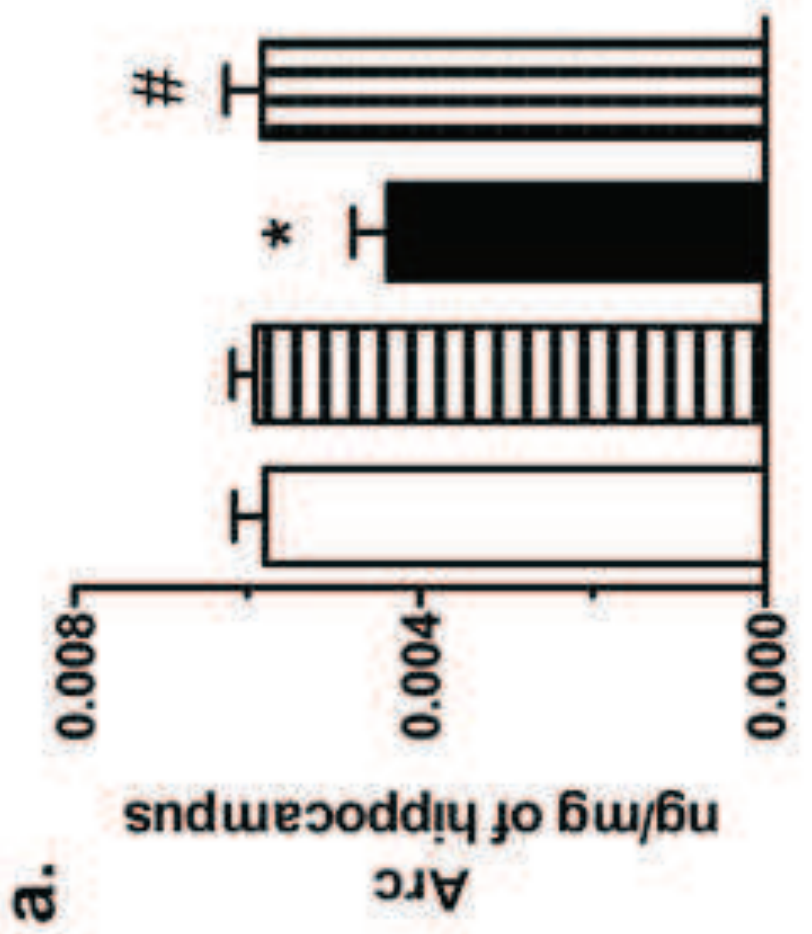

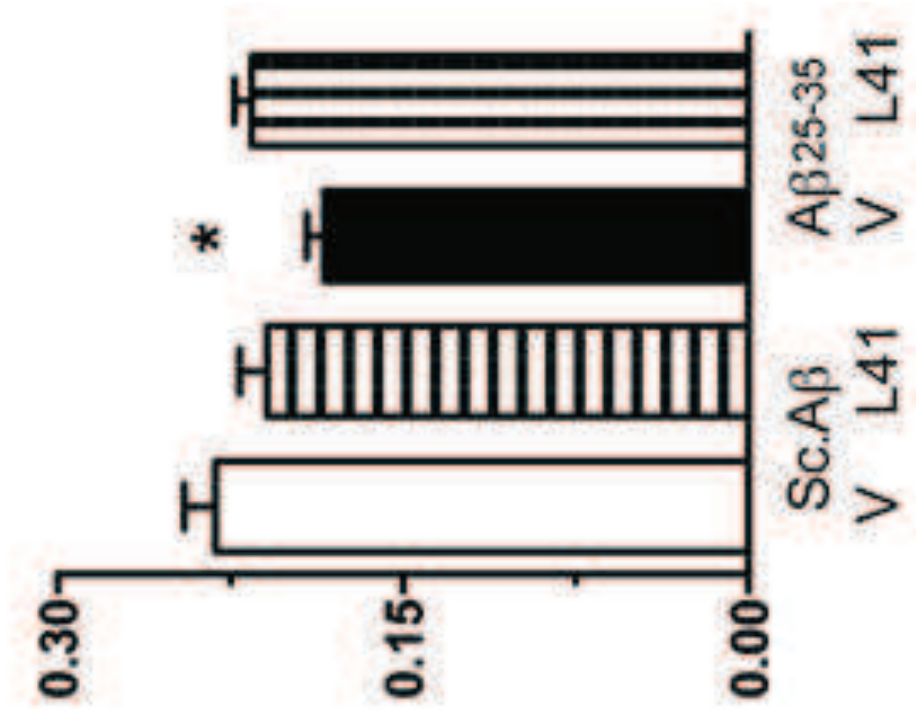

snduesodd!̣ to $6 \mathrm{w} / 6 \mathrm{6u}$

ச u!skydołdeuKs

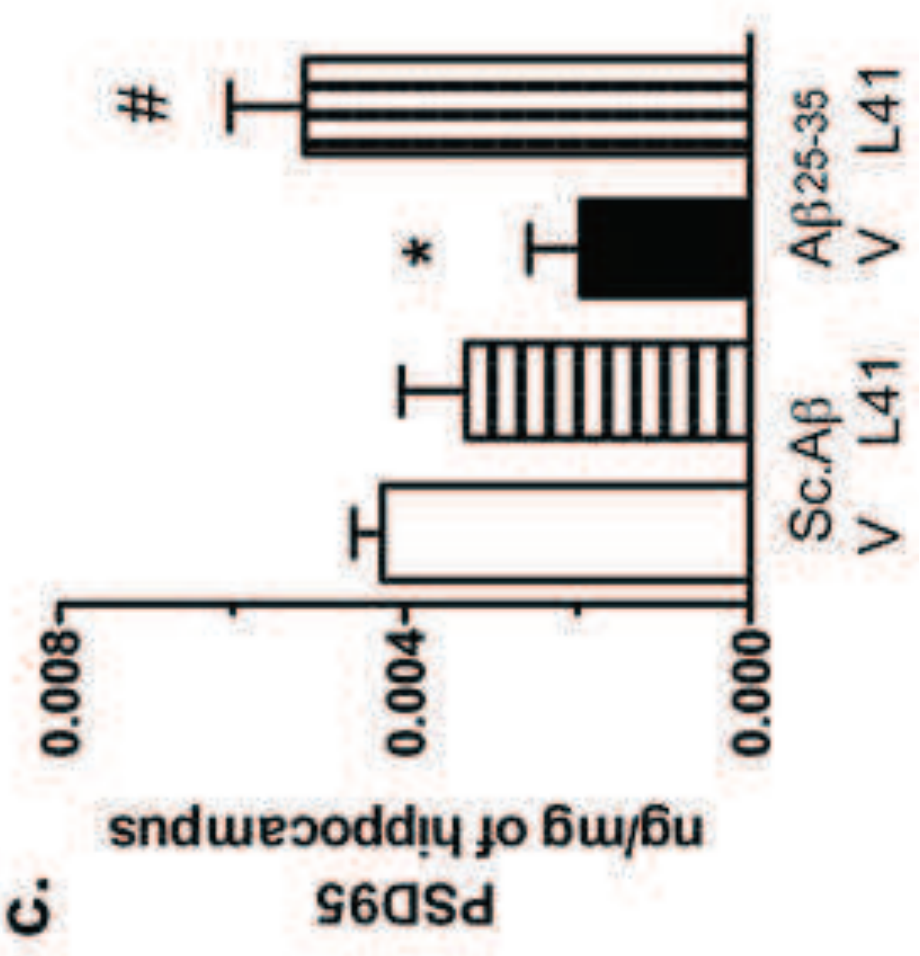

